Leibniz-Institute of

Freshwater Ecology

and Inland Fisheries

\title{
Unravelling metal mobility under complex contaminant signatures
}

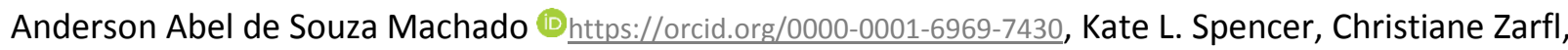
Francis T. O'Shea (1) https://orcid.org/0000-0002-0808-7441

DOI

10.1016/j.scitotenv.2017.11.239

Original publication date

13 December 2017 (Available online)

Document version

Accepted manuscript

Published in

Science of The Total Environment

Citation (Vancouver)

Machado AAdS, Spencer KL, Zarfl C, O'Shea FT. Unravelling metal mobility under complex contaminant signatures. Science of the Total Environment. 2018;622-623:373-84. 


\section{Unravelling metal mobility under complex contaminant signatures}

Anderson Abel de Souza Machado ${ }^{a, b, c^{*}}$; Kate L. Spencer ${ }^{c}$; Christiane Zarfl ${ }^{d}$; Francis T. O’Shea ${ }^{c, e}$

${ }^{a}$ : Leibniz-Institute of Freshwater Ecology and Inland Fisheries. Müggelseedamm 310, 12587 Berlin, Germany.

b: Department of Biology, Chemistry and Pharmacy, Freie Universität Berlin. Altensteinstr 6, 14195 Berlin, Germany.

${ }^{c}$ : School of Geography, Queen Mary University of London. Mile End Road, London E1 4NS, UK.

${ }^{d}$ : Center for Applied Geosciences, Eberhard Karls Universität Tübingen. Hölderlinstr 12, 72074 Tübingen, Germany.

${ }^{\text {e}}$ : Geography Department, Kings College London, Strand, London, WC2R 2LS.

*Corresponding author:

First name: Anderson Abel

Surname: de Souza Machado

Email: machado@igb-berlin.de

Tel: +4903064181942

Müggelseedamm 310, 12587 Berlin, Germany. 


\section{Abstract:}

Metals are concerning pollutants in estuaries, where contamination can undergo significant remobilisation driven by physico-chemical forcing. Environmental concentrations of metals in estuarine sediments are often higher than natural backgrounds, but show no contiguity to potential sources. Thus, better understanding the metal mobility in estuaries is essential to improve identification of pollution sources and their accountability for environmental effects. This study aims to identify the key biogeochemical drivers of metal mobilisation on contaminated estuarine sediments through (1) evaluation of the potential mobilisation under controlled conditions, and (2) investigation of the relevance of metal mobilisation for in situ pollution levels in an area with multiple contaminant sources. Sediments from a saltmarsh adjacent to a coastal landfill, a marina, and a shipyard on the Thames Estuary (Essex, UK) were exposed in the laboratory $\left(24 \mathrm{~h}, \mathrm{~N}=96,20^{\circ} \mathrm{C}\right)$ to water under various salinity, $\mathrm{pH}$, and redox potential. Major cations, Fe(II), and trace metal concentrations were analysed in the leachate and sediment. Salinity, $\mathrm{pH}$ and redox had a significant effect on metal mobilisation $(p<0.001)$, e.g. under certain conditions Fe(II) leaching was increased 1000-fold. Measurements in situ of surface and subsurface sediment cores revealed that landfill proximity poorly explained metal spatial distribution. However, physicochemical parameters explained up to $97 \%$ of geochemically normalized metal concentrations in sediments. Organic matter and $\mathrm{pH}$ were dominant factors for most of the metal concentrations at the sediment surface. At subsurface, major cations ( $\mathrm{Ca}, \mathrm{Na}, \mathrm{Mg}$ and $\mathrm{K}$ ) were determinant predictors of metal concentrations. Applying the empirical model obtained in the laboratory to geochemical conditions of the studied saltmarsh it was possible to demonstrate that Fe mobilisation regulates the fate of this (and other) metal in that area. Thus, present results highlight the importance of metal mobility to control sediment pollution and estuarine fate of metals. 




Legend
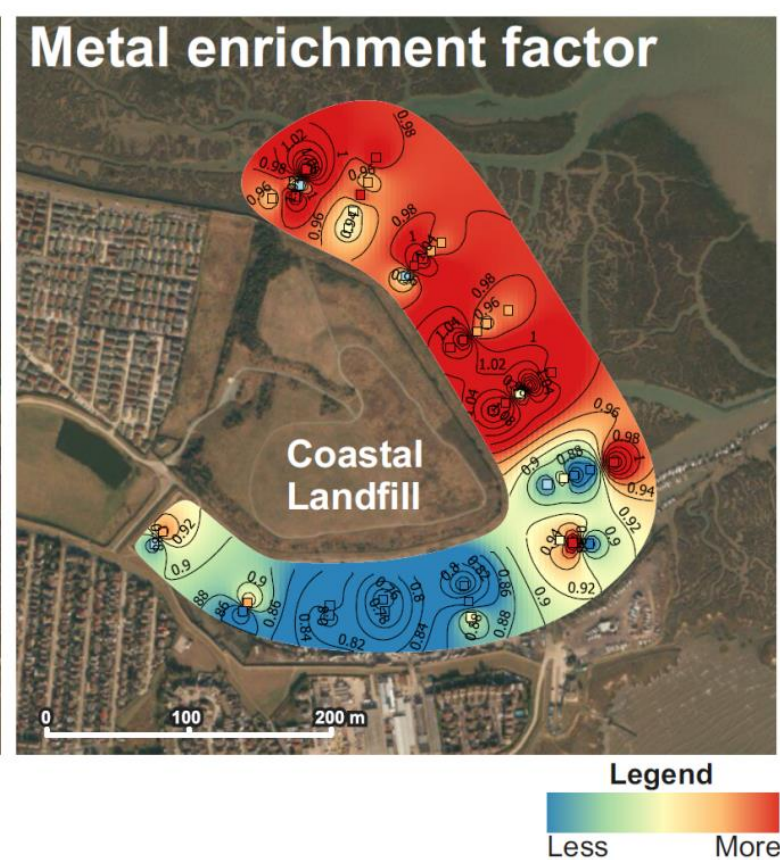

\section{Highlights:}

- Laboratory experiments and field survey were performed for pollution assessment.

- Contaminated sediments leached significant amounts of metals to overlying water.

- Metal mobilisation varied 1000-fold depending on sediment $\mathrm{pH}$, salinity, and redox.

- Metal mobility affected concentration in sediment and contamination signatures.

- Assessment of metal mobility in estuarine sediments is essential to infer environmental impacts.

Keywords: coastal landfill, contaminant mixtures, estuaries, pollution assessment, sediment geochemistry. 


\section{Introduction}

Estuaries are transitional ecosystems between land and sea that provide a multitude of services (Millennium Ecosystem Assessment, 2005). These areas are amongst the most biologically productive of the planet, and therefore of extreme relevance for marine and freshwater biodiversity protection. Additionally, the provisioning of privileged access to marine, freshwater and continental resources made estuarine systems preferable places for urbanization and industrialization (Kennish, 1991). In fact, many important large metropolitan areas of current commercial and industrial centres, such as London, New York, Shanghai, Lagos, Istanbul and Tokyo are situated in estuarine systems. Therefore, estuarine environments have globally experienced both historical and current intense anthropogenic activities and consequent contamination (Chapman and Wang, 2001; Ridgway and Shimmield, 2002).

Metal contaminants have been traditionally problematic in estuaries because they tend to present non conservative behaviour, while still concentrating and accumulating in estuarine sediments (Machado et al. 2016). In fact, metal-contaminated sediments are commonly reported as of potential concern for the quality of estuarine waters and benthic organism worldwide (Bianchi, 2007). For instance, legacy contaminated sediments in estuaries from Southeast England might display up to $70 \%$ of bioavailable metals, many of which at levels that threat wildlife and environmental services (Spencer and MacLeod, 2002). Many estuaries receive substantial inputs of metals such as $\mathrm{Cd}, \mathrm{Cu}, \mathrm{Cr}, \mathrm{Hg}, \mathrm{Pb}, \mathrm{Zn}$ that concentrate in the sediment at levels up to one million-fold higher than the water concentrations (Förstner and Wittmann, 1979, Zwolsman et al. 1993, Attrill and Thomes, 1995).

On the other hand, the non-conservative behaviour of metals (Machado et al. 2016) driven by mobilisation hampers the assessment of pollution sources and misleads inference of pollution levels. For instance, the Newlands saltmarsh (Thames Estuary, UK) presents metal concentrations at concerning levels but with weak association to the main known sources (O'Shea 2016 
https://qmro.qmul.ac.uk/xmlui/handle/123456789/12995), which obstructs accountability for pollution. Indeed, O'Shea (2016) determined that a combination of proximity to contaminant source and postdepositional mobility accounted for spatial variability in metal concentrations in those intertidal sediments. Many of the physic, chemical and biological gradients present in estuaries affect the metal speciation, partitioning, transport, and consequently spatial distributions (Zwolsman et al. 1993). As an example, the decay of organic matter, periodic flooding, and air exposure of sediments on intertidal areas provoke a cyclic covariation of pH and redox (Machado et al. 2016), with consequent changes on chemical speciation and cycling of several metals (Du Laing et al. 2009c). The diagenetic remobilisation and the difference on sediment $\mathrm{pH}$ and salinization due to seawater inflow similarly affects metal speciation and fate (Zwolsman et al. 1993; Du Laing et al. 2009a, b; Johnston et al. 2011,). As a result, complex contaminant signatures arising from multiple sources and high environmental mobility make identification of potential impacts particularly challenging.

Notwithstanding, metal pollution is still investigated in estuaries as in fully fresh or marine sediments, i.e. in terms of continuity of high contaminant levels to the contamination sources (Chapman and Wang, 2001). That is partially because it is still unclear how relevant the impacts of metal mobility are in estuarine sediments near contamination sources. Consequently, such lack of information obstructs a realistic understanding of the estuarine pollution and a quantification of the metal mobilised from the sediment to the bioavailable water fraction that mostly impacts aquatic biota.

The present study aimed to quantify the potential effects of the key biogeochemical drivers of metal mobilisation on the metal pollution levels in estuarine sediments. Therefore, laboratory experiments, field measurements and modeling methods were combined in a manner that could be easily implemented in environmental health assessments. The laboratory experiments aimed to provide an estimation of the potential for metal leaching on surface sediments and served as basis for empirical models of geochemical metal mobilisation. Additionally, the in situ relationships between metal enrichment factors and sediment geochemistry were investigated in an intertidal area surrounded by multiple potential 
contamination sources to compare the influence of mobilisation and proximity to the emission source. The study site chosen here is under influence of a historical coastal landfill and multiple current metal sources (i.e. shipyard and docking area) in one of the estuaries most heavily impacted by metal pollution in the world (Thames Estuary, UK). Metal enrichment factors were used for the assessment of pollution level because they represent the most commonly employed proxy of metal contamination. Finally, an empirical model from laboratory experiments was combined with the in situ sediment geochemistry to compare pollution levels and metal mobilisation. This approach allowed inference of the importance of metal mobility for pollution levels and its interference on the identification of metal sources in estuarine systems.

\section{Material \& Methods}

For the purpose of the present study we define some terms that are broadly used in pollution science with potentially ambiguous meaning. The term "metal immobilisation" is defined as the collection of processes such as adsorption, absorption, precipitation and co-precipitation, crystallization that remove metal from the water column to a solid sedimentary phase (Förstner and Wittmann, 1979). The term "metal mobilisation" is then used here as the sum of physical, chemical and biological processes complementary to immobilisation that result into a transfer of metal as dissolved or particulate to the aqueous phase with potential to be transported by water hydrodynamics. The term "metal mobility" is thus defined as the interaction of immobilisation and mobilisation, in which low metal mobility implies high net immobilisation whereas high metal mobility implies high net mobilisation. Moreover, salinity is presented here as practical salinity units 1978 (Unesco/ICES/SCOR/IAPSO, 1981), which is proportional to the conductivity of the sample and its salt content. Therefore, the term salinization is used here as the increase in salinity (and salt contents) of water, slurry or sediments. 


\subsection{Study area}

The Thames Estuary is a tidally dominated estuary with strong anthropogenic influence and noticeable metal contamination (Spencer and MacLeod, 2002; van der Wal and Pye, 2004; Vane et al; 2016). This estuary is amongst the first industrial centres in the world, which summed to the influence of the City of London are the main the causes of a high metal pollution (Attrill and Thomes, 1995). Moreover, several landfills were constructed based on the attenuation principle in the Thames intertidal areas (O'Shea 2016 https://qmro.qmul.ac.uk/xmlui/handle/123456789/12995), which today constitute potential additional contamination source.

The study area is situated on an intertidal saltmarsh of the Thames Estuary (south east England, $58^{\circ} 21^{\prime} 25^{\prime \prime}$ $\mathrm{N}$ and $18^{\circ} 37^{\prime} 37^{\prime \prime} \mathrm{E}$ ) receiving both current and legacy contamination from multiple sources (O'Shea 2016 https://qmro.qmul.ac.uk/xmlui/handle/123456789/12995), including the Newlands historic landfill, and the shipyard and docking areas on the Oyster Creek (Fig. 1). The Newlands Landfill, hereafter referred as Newlands, is a historical coastal landfill situated on the northern bank of lower portion of the Thames Estuary (Essex, UK). As many other historic coastal landfills from western Europe, Newlands was constructed with no basal or side wall engineering, which allowed release of contaminated leachate, relying on attenuation by surrounding sediments (O'Shea 2016 https://qmro.qmul.ac.uk/xmlui/handle/123456789/12995). The site was actively receiving waste from 1954 to 1989 when it was dumped approximately 1,000,000 $\mathrm{m}^{3}$ of diverse toxic waste including oilcontaminated material from beach clean ups as well as household and commercial waste (Caulmert Limited, 2011a, b). The Newlands is currently underneath the recreational Canvey Heights Country Park. At the south side of the Newlands there is the Oyster Creek, in which many storm water drains and docks from the Small Gains Marina and the Island Yatch Club are located. The metal distributions in that area have been investigated and suggest that historically the landfill was a source of Cr, Cu, Pb and Zn (O'Shea 2016 https://qmro.qmul.ac.uk/xmlui/handle/123456789/12995) which is now recorded at depth in the saltmarsh sediments. 


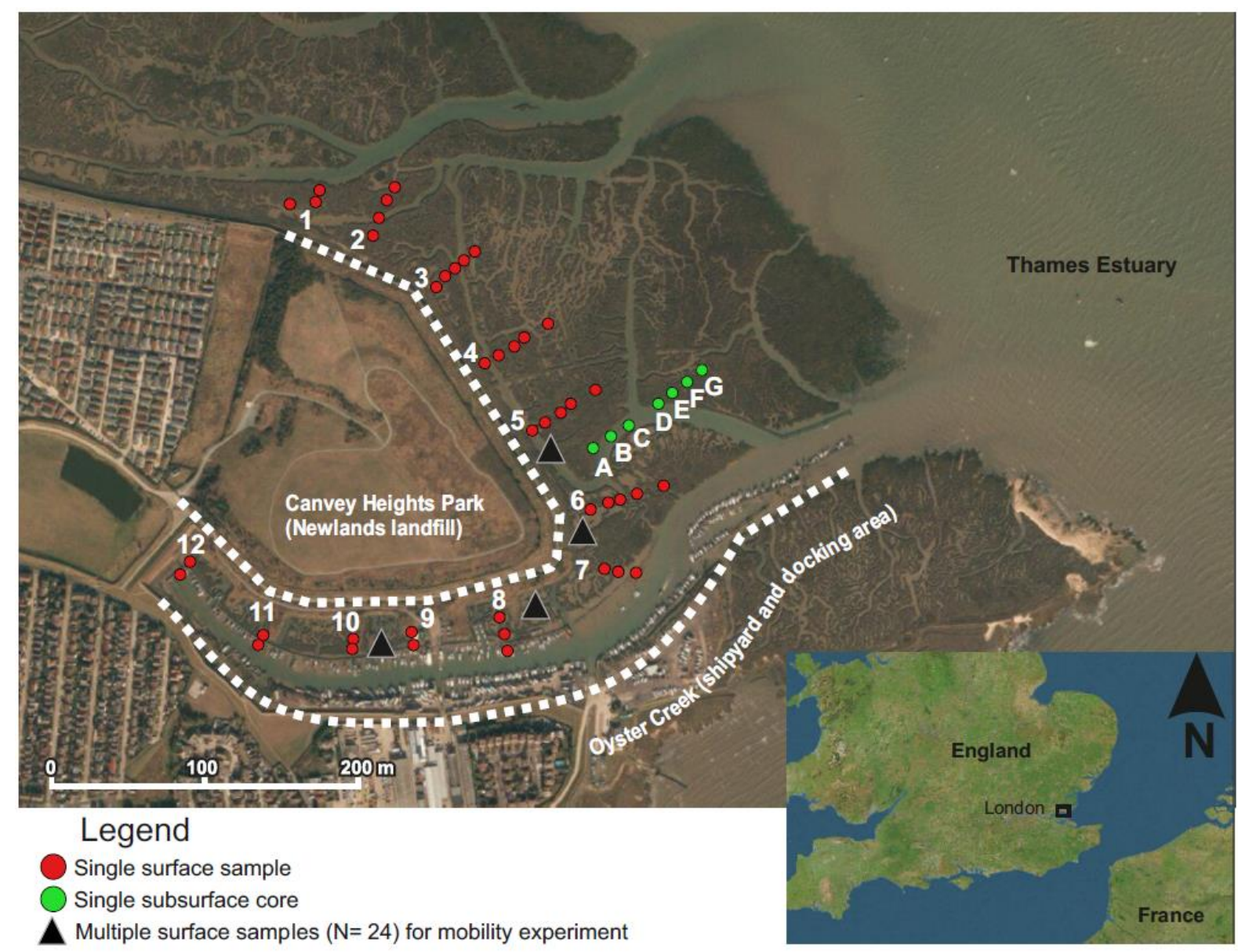

Figure 1: Schematic of the study area: intertidal saltmarshes adjacent to the Canvey Heights Country Park (Essex, UK). The main potential fronts of metal contamination (the historic Newlands landfill and Oyster Creek shipyard and docks) are highlighted with a white dashed line. Transects are denoted by numbers (112), while subsurface individual cores are represented by uppercase letters (A-G). Each triangle points the area where 24 individual samples were taken for the leachate experiment.

\subsection{Laboratory experiments}

The main goal of the experiments was to quantify the metal leaching from surface sediments under various redox, salinity and $\mathrm{pH}$, so that the rate of metal leaching was used to develop empirical models of potential 
metal mobilisation on estuarine sediments. For that surface sediment rings $(2 \mathrm{~cm})$ were collected in 4 points (24 samples each) of the intertidal mud flat (Fig. 1). The samples were then wrapped with cling film, brought to the Geography laboratory of Queen Mary, University of London in refrigerated coolers, and stored at $4{ }^{\circ} \mathrm{C}$ for up to 4 weeks. Redox potential (Eh) of the slurry ranged from $-229 \mathrm{mV}$ to $-1 \mathrm{mV}$.

Sediment slurries were prepared with $10 \pm 0.1 \mathrm{~g}$ wet sediment placed in $50 \mathrm{~mL}$ conical centrifuge plastic tubes with $25 \mathrm{~mL}$ of nanopure water. The original $\mathrm{pH}$ of this sediment slurry ranged from 7.4 to 8.5 and it was recorded with a pH probe (VWR pH110). Four treatments of salt were added to experimental slurries ( $0.000 \mathrm{~g}, 0.125 \mathrm{~g}, 0.375 \mathrm{~g}$ or $0.875 \mathrm{~g}$ of sea salt - $\$ 9883$, Sigma Aldrich) were considered to investigate effects of salinization on metal mobility. The sea salt used in this study is a composition of $\mathrm{Cl}, \mathrm{Na}, \mathrm{SO}_{4}, \mathrm{~K}, \mathrm{Ca}$, $\mathrm{HCO}_{3}, \mathrm{Sr}, \mathrm{B}, \mathrm{Br}, \mathrm{I}, \mathrm{Li}, \mathrm{F}, \mathrm{Mg}$ and trace elements of typical sea water (supplementary table A. 1). After salt addition, the slurry was stirred with vortex for $\sim 1 \mathrm{~min}$. The mass of marine salt added created leachates with salinities of $0,5,15$ and 30 had complete dissolution occurred. It is worth to mention that only partial dissolution was achieved since the sediment interacted with salinity adjustments. A summary of theeffect of salt addition on salinity and major ion concentration on the leachates is presented on supplementary figure A. 1, and supplementary table A. 2.

After salt addition, the original $\mathrm{pH}$ was adjusted by adding hydrochloric acid $1 \mathrm{M}$ or sodium hydroxide $1 \mathrm{M}$, which resulted in a pH initial ranging from 5.9 to 9.1. The experimental slurry (with modified salinity and $\mathrm{pH}$ ) was then gently shaken for $24 \pm 1 \mathrm{~h}$ at $24 \pm 2{ }^{\circ} \mathrm{C}$. After this $24 \mathrm{~h}$-period of water-sediment interaction, the $\mathrm{pH}$ was recorded as $\mathrm{pH}$ final (table 1). Redox potential (Eh) of the slurry was also determined with a redox probe (VWR pH110). The experimental slurry was then centrifuged for $10 \mathrm{~min}$ at $3000 \mathrm{rpm}$, and the resulting supernatant was considered the leachate for the purpose of the present study. Salinity in the leachate was measured (VWR pH110), and $1 \mathrm{~mL}$ of it was immediately preserved for Fe(II) analysis. We devoted especial attention to iron behaviour as it is known to affect the fate of other metals, and because Fe(II) was an important metal species that we could measure in a simpler manner without filtering the leachate (see section 2.4.3). The remaining leachate was passed through filters with $8 \mu \mathrm{m}$ 
mesh (Whatman 542) for later ICP OES quantification of total mobilised metal during leaching experiment. Despite filters of $0.45 \mu \mathrm{m}$ or smaller are commonly used to infer dissolved or bioavailable metal, the current study focused on the mass of metal mobilised, which is more accurately assessed via total metal proxies. In this sense, the $8 \mu \mathrm{m}$ used here constituted the minimum filtering required to quantify total metal with the ICP OES procedures used here. Yet, during this filtering part of the colloidal metal was retained, as discussed in the supplementary material A (Box A. 1). Inferences about bioavailable metal are beyond the scope of the current study.

Table 1: Range of geochemical parameters measured at the end of $24 \mathrm{~h}$ on laboratory experiments. Salinity and $\mathrm{pH}$ were arranged as multivariate, $\mathrm{pH}$ and redox as covariate (Supplementary figure A. 2).

\begin{tabular}{lcc}
\hline \hline & Range & Experimental size \\
\cline { 2 - 3 } Parameter & Min to Max & $\mathrm{N}^{\mathrm{a}}$ \\
& & \\
$\mathrm{pH}$ & 6.3 to $8.6^{\mathrm{b}}$ & 96 \\
Salinity & 2.6 to 31.5 & 96 \\
Eh $(\mathrm{mV})$ & -229 to -1 & 96
\end{tabular}

a: 24 surface samples were collected at each of the 4 points of the saltmarsh (Fig. 1) and posteriorly equally distributed along the range of pH and salinity treatments.

b: the monitored variation of $\mathrm{pH}$ within the experimental $24 \mathrm{~h}$ were generally smaller than $12 \%$.

\subsection{Field assessment}

The field data within this paper for surface and subsurface metal concentrations and enrichment factors are presented elsewhere (O’Shea 2016 https://qmro.qmul.ac.uk/xmlui/handle/123456789/12995), therefore only a brief overview of the data collection methods is outlined here.

Surface grab samples were taken every $50 \mathrm{~m}$ in triplicate along 12 radial transects perpendicular to the site boundary (Fig. 1). Additionally, seven sediment cores were extracted at $10 \mathrm{~m}$ intervals along 
a transect perpendicular to the site boundary using a polycarbonate pipe for the first $30 \mathrm{~cm}$ or a Russian corer for deeper samples (Jowsey, 1966). Samples kept at $-12^{\circ} \mathrm{C}$ until required.

Subsurface samples were analysed at $5 \mathrm{~cm}$ intervals for the top $1 \mathrm{~m}$, then $10 \mathrm{~cm}$ intervals at depths below this. Samples were homogenized and split, with a sub-sample used for $\mathrm{pH}$, particle size and organic matter content while the other was freeze-dried for 24 hours for later metal analysis. Original pH was measured in these samples as in the leachate experiments.

The surface sediments were classified as silty clay or clayey silt (Shepard, 1954), with predominance of mud-sized $(<3.9 \mu \mathrm{m})$ and silt-sized $(3.9-63 \mu \mathrm{m})$ sediment fractions. There was only little spatial variation on surface grain size. However, subsurface sediment shifted from clayey silt near the sediment surface to silty sand at depth (deeper than $70 \mathrm{~cm}$ ) (O'Shea 2016 https://qmro.qmul.ac.uk/xmlui/handle/123456789/12995). Further mineralogical characterization of the sediment samples was not performed.

Data from these field samples are discussed within the section 3.2 and 3.3 and combined with laboratory experimental data for the mobilisation presented in section 3.4.

\subsection{Additional physico-chemical parameters analysed}

A broad suite of geochemical parameters influencing metal mobility were measured in both leachate experiment and field assessment data as described below. Procedures reported in section 2.4.1 to section 2.4.3 refer to laboratory leachate experiment. Methods for the field assessment are similar and can be found in more detail in O'Shea 2016 (https://qmro.qmul.ac.uk/xmlui/handle/123456789/12995).

\subsubsection{Water percentage and Loss of ignition}


Water percentage was quantified by the mass difference between overnight dried $\left(60^{\circ} \mathrm{C}\right)$ sediment and the initial a wet mass ( $24.2 \pm 3.3 \mathrm{~g}$ ). Loss of ignition (LOI) was then measured as a proxy for organic matter content on the sediment. For that a mass of $13.4 \pm 2.2 \mathrm{~g}$ of dried sediment was ignited in a furnace $\left(550{ }^{\circ} \mathrm{C}\right.$, $5 \mathrm{~h}$ ). The difference on weight before and after ignition was interpreted in terms of percentage of organic matter combusted.

\subsubsection{Aqua Regia extraction}

Trace metals were extracted from all sediment samples on a hotplate using Aqua Regia $\left(\mathrm{HNO}_{3}: 3 \mathrm{HCl}\right)$. This method quantifies pseudototal metal, which provides insights on the potential environmentally mobile and bioavailable metal. Therefore, such metal extracted is considered as environmentally available metal (National Water Research Institute, 2001) and this terminology is adopted here.

All the materials in contact with metals during leachate experiment and Aqua Regia extraction were washed with nitric acid $10 \%$ during $24 \mathrm{~h}$ and rinsed 3 times with nanopure water. All the chemicals used in the present study were analytical grade. Sediment from metal leaching experiment and from field assessment were freeze-dried overnight (vacuum, $-56^{\circ} \mathrm{C}$ ). The extraction involved placing $0.50 \pm 0.02 \mathrm{~g}$ of sediment in Erlenmeyer flasks, adding freshly prepared Aqua Regia, and heat this mixture for in hot plate (5 $\mathrm{h}, \sim 85^{\circ} \mathrm{C}$ ) (Chen and Ma, 2001). The Aqua Regia was then filtered (542 Whatman, $8 \mu \mathrm{m}$ ) and made up to $50 \mathrm{~mL}$ with nanopure water. To assess accuracy of metal extraction additionally 2 certified materials (SUD1- Environment Canada, and the CRMLGC 6187) and method blanks were analysed in triplicate (Supplementary material, Table A.5). Also, two samples were measured in duplicate, which were considered together with the certified materials to assess extraction precision (Supplementary material, Table A.5). Metal extracts were kept at $4{ }^{\circ} \mathrm{C}$ until analysis. 


\subsubsection{Metal quantification}

$\mathrm{Fe}(\mathrm{II})$ in the leachate was measured with the colorimetric method based on the reaction of Fe(II) with the 1,10- phenanthroline as in Lee and Stumm (1960). Other metal concentrations ( $\mathrm{Al}, \mathrm{Co}, \mathrm{Fe}, \mathrm{Li}, \mathrm{Mn}, \mathrm{Pb}, \mathrm{Sr}$ ) on the leachate and sediments were quantified by inductively coupled plasma optical emission spectrometry (ICP OES) on a Varian Vista-Pro ICP OES instrument using internal standard settings of the Geography laboratory of Queen Mary, University of London. Analytical further information and quality control data is presented in supplementary tables A. 3, A. 4 and A. 5).

\subsubsection{Geochemical speciation model with Visual MINTEQ}

In order to provide mechanistic insights on the geochemical processes driving the mobility of metals in the laboratory experiments, computations of equilibrium concentrations of $\mathrm{Fe}$ and trace metal species in the pore water were performed with Visual MINTEQ 3.0. In total 96 scenarios were computed (one for each leachate) according to table 2 . Note that such settings were designed to consider the effects of parameters with the strongest association with metal mobility in the laboratory and in the field, namely Fe mobility and its relationship to $\mathrm{pH}$ and organic matter (see section on Results and Discussion). Such computations did not consider all the activity of ions from saltwater and sediments or the full diversity of mineral and sorption sites potentially available in those systems. This simplification might limit the accuracy of Visual MINTEQ outputs. Introduction of these variables in the model would cause a very great number of possible reactions and products that lead to numerical instabilities. Therefore, the model outputs displayed in the figure of Box 1 should be interpreted as an indication of general patterns only.

Table 2: Parameters for the computations of metal speciation with Visual MINTEQ. 


\begin{tabular}{|c|c|c|}
\hline Parameter & \multicolumn{2}{|l|}{ Model settings } \\
\hline $\mathrm{pH}$ & Varied as $\mathrm{pH}$ measured for each sample & Variable with major effects on Fe mobility \\
\hline Eh $(m V)$ & Constant at -150 & Average redox of sediments \\
\hline Temperature $\left({ }^{\circ} \mathrm{C}\right)$ & Constant at 24 & Experimental condition \\
\hline $\mathrm{DOC}\left(\mathrm{mg} \mathrm{L}^{-1}\right)$ & $\begin{array}{l}\text { Varied according to measured at each sample } \\
\text { The concentration of DOC was estimated based on the empirical quadratic } \\
\text { relationship between LOI and DOC by Craft et al. 1990. The reactivity of DOC to } \\
\text { metals was simulated with the Stockholm Humic Model (SHM) within Visual } \\
\text { MINTEQ. The SHM accounts for metal complexation by both dissolved and } \\
\text { particulate organic matter. }\end{array}$ & $\begin{array}{l}\text { Variable with major effects on metal } \\
\text { concentrations on the field surveys }\end{array}$ \\
\hline $\begin{array}{l}\text { Adsorption surface } \\
\text { model }\end{array}$ & $\begin{array}{c}4.8 \mathrm{~g} \mathrm{~L}^{-1} \text { of matter allocated to ferrihydrite, and the Hydrous Ferric Oxide } \\
\text { Model (HFO- Dzombak \& Morel) was used to compute surface complexation of } \\
\text { metals to iron oxyhydroxide minerals. }\end{array}$ & $\begin{array}{l}\text { This represents the allocation of } ~ 80 \% \text { of } \\
\text { total Fe measured to the HFO model, which } \\
\text { is the most complete database for the } \\
\text { interaction of precipitated metal minerals } \\
\text { and other ions. }\end{array}$ \\
\hline $\begin{array}{l}\text { Counter-ion } \\
\text { function }\end{array}$ & Activated & $\begin{array}{l}\text { Accounts for the changes in the surface } \\
\text { charges resulting from ion-surface } \\
\text { interactions. }\end{array}$ \\
\hline $\mathrm{Fe}(\mathrm{II})$ & Varied as $\mathrm{Fe}^{2+}$ for each sample & $\sim 20 \%$ of the total Fe measured \\
\hline Cobalt & Varied as $\mathrm{Co}^{2+}$ for each sample & Total Co measured for each sample \\
\hline Manganese & Varied as $\mathrm{Mn}^{2+}$ for each sample & Total Mn measured for each sample \\
\hline Lead & Varied as $\mathrm{Pb}^{2+}$ for each sample & Total Pb measured for each sample \\
\hline Strontium & Varied as $\mathrm{Sr}^{2+}$ for each sample & Total Sr measured for each sample \\
\hline Lithium & Varied as $\mathrm{Li}^{2+}$ for each sample & Total Li measured for each sample \\
\hline & $\begin{array}{r}\text { Other parameters were set as default of Visual MINTEQ } 3.0 \text { for all samples, and } \\
\text { Visual MINTEQ for further information on assumptions and }\end{array}$ & $\begin{array}{l}\text { eaders are referred to user guide of } \\
\text { arametrization. }\end{array}$ \\
\hline
\end{tabular}

\subsubsection{Geochemical normalisation and enrichment factors}

Metal concentrations in sediments vary with grain size, which makes necessary to normalize environmental metal concentrations (Kerten and Smedes, 2002). Variations in the distribution of fine sediments, which are negatively charged surfaces and have large surface/volume ratios that increase cation exchange capacity, affects the concentrations of sediment-bound metals (Förstner and Wittmann, 1979). Thus, different types of "normalisation" of metal concentration are used to interpret environmental metal concentrations (Kerten and Smedes, 2002). Broadly, normalisation consists to divide measured metal concentrations by a proxy element that could account for the different adsorption at various grain sizes. Al and Li are amongst the most common normalizing elements (Kerten and Smedes, 2002) and were adopted in the present study. Therefore, metal concentrations presented here were normalized by the Al as this 
metal was used in relevant estuarine geochemistry studies (Zhang and Liu, 2002). Al concentrations needed to be normalized by Li to avoid mathematical artefacts of normalization.

Enrichment factor (EF) was also computed as this parameter is perhaps the most common indicator used for environmental assessment of metal pollution. EF was calculated empirically according to equation 1. The background concentrations for the studied area were determined by O'Shea 2016 (https://qmro.qmul.ac.uk/xmlui/handle/123456789/12995), i.e. the average metal concentrations between 3.4 and 4.4 m deep of core 2.

$$
\text { Equation } 1 \quad E F=\frac{\left(\frac{M_{s}}{N_{s}}\right)}{\left(\frac{M_{b}}{N_{b}}\right)}
$$

Where:

$E F=$ Enrichment factor

$M_{s}=$ Metal concentration in the sample

$N_{s}=$ Normalizing metal in the sample

$M_{b}=$ Background metal concentration for the studied area

$N_{b}=$ Background normalizing metal concentration for the studied area

\subsection{Statistical methods and data presentation}

Significant effects of geochemical parameters on metal mobilisation and sediment metal enrichment factors were detected with Kruskal-Nemenyi test with Tukey post hoc (Sachs, 1997) or linear regressions with the "Im" function from software R (R Core team 2013). The empirical linear relationships between geochemical parameters and metal mobility are presented in the figures so that interested readers could potentially compare them to values from other studies. All statistical analyses were performed with $\alpha=$ 0.05 . 
The empirical linear model derived from the laboratory experiments (Fig. 2) was used to estimate Fe(II) leaching from in situ sediments. Then, spatial distribution of Fe enrichment factors, and Fe(II) leaching maps were created on the software QGIS 2.14.1 with interpolated surface sediment data. Interpolation was performed by inverse distance weighting, and contour lines were extracted for EF (every 0.02) and metal mobilisation (every 10) intervals.

\section{Results and discussion}

In the next paragraphs the results on the potential for metal leaching from contaminated sediments are discussed in terms of drivers of metal mobilisation. Secondly, the influence of sediment geochemistry is compared to the proximity to potential contamination sources. Finally, the relevance of metal mobilisation to metal levels in that tidal flat and how ignoring metal mobilisation might mislead environmental health assessment are discussed in the context of estuarine sediments with complex contaminant signatures.

\subsection{Potentially high metal leaching in estuarine sediments}

The metal species with highest mobilisation flux was Fe(II). Mobilisation of Fe(II) varied from less than 0.2 up to $267.5 \mu \mathrm{g} \mathrm{Fe}(\mathrm{II}) \mathrm{g}^{-1}(\mathrm{dw}) \mathrm{d}^{-1}$ depending mostly on $\mathrm{pH}$ (Fig. 2). In fact, the empirical model devised here predicts a 2.66-fold on Fe(II) mobilisation for an increment an unit of $\mathrm{pH}$ (see equation on Fig. 2). The geochemical explanation for such a great changes in Fe(II) mobility might be on the formation of Fe hydroxides (see Box 1). Redox potential also affected Fe(II) leaching $(\mathrm{p}<0.001)$, with maximum leaching occurring between -150 and $-50 \mathrm{mV}$ (Supplementary figure B. 1). Salinization presented only mild effects, with more saline slurry yielding leachates with slight higher Fe(II) concentration (Supplementary figure B. 1). 




Figure 2: Effects of $\mathrm{pH}$ on the mobilisation of Fe(II). The white, light grey, dark grey and black filled circles represent respectively $0.000 \mathrm{~g}, 0.125 \mathrm{~g}, 0.375 \mathrm{~g}$ or $0.875 \mathrm{~g}$ of marine salt added to the experimental slurry.

Sediment geochemistry also strongly influenced the leaching of $\mathrm{Al}, \mathrm{Co}, \mathrm{Li}, \mathrm{Mn}, \mathrm{Pb}$ and $\mathrm{Sr}$. For the total mobilised metal, salinity and pH changes jointly accounted for $80 \%$ of metal leaching (Fig. 3). In this context, salinization is believed to increase metal leaching due to a combinatory effect of anions and cations in affecting the ionic forces on the slurry (Förstner and Wittmann, 1979; Bianchi, 2007). Saltwater anions as chloride form soluble complexes with weakly adsorbed metals, therefore enhancing solubility (Machado et al. 2016). That is because metals weakly adsorbed as Cd might interact with chloride and sulphate to form soluble inorganic species (Greger et al., 1995). Concurrently, Ca and Na cations can displace both weakly and moderately sorbed metals such as $\mathrm{Cr}, \mathrm{Cu}, \mathrm{Zn}$ and Pb (Fairbrother et al. 2007). Thus, via such mechanisms metal adsorption can be prevented as well as metal desorption increased. 


\section{Box 1. Geochemical insights on the effects of $\mathrm{pH}$ on the behaviour of $\mathrm{Fe}(\mathrm{II})$ and trace metals}

The computations of $\mathrm{Fe}$ (II) speciation with the chemical equilibrium model Visual MINTEQ suggest that the effects of $\mathrm{pH}$ on $\mathrm{Fe}$ (II) leaching are explained by a decrease in dissolved Fe(II) in combination to an increase in adsorbed Fe(II) (Fig. Box $1 \mathrm{~A}$ ). Moreover, the concentrations of Fe hydroxides were predicted to increase up to 6 orders of magnitude (Fig. Box 1B) with the increment of $\sim 2.5 \mathrm{pH}$ units. Indeed, the concentration of $\mathrm{H}^{+}$is reported to affect hydrolysis of metals, which was generally estimated by Hietanen and Sillén (1954) as:

$$
q \mathrm{Me}^{z+}+p \mathrm{H}_{2} \mathrm{O} \rightleftharpoons \mathrm{Me}_{q} \mathrm{OH}_{p}^{(q z-p)+}+p \mathrm{H}^{+}
$$

Where " $q$ " is the number of metal units in the complex, "Me" is the metal element, " $z$ " is the charge of $M e$ ion, " $p$ " is the number of $\mathrm{OH}$ (hydroxyl) in the complex, and $\mathrm{H}$ is the hydrogen ion. Such hydrolytic reaction might produce one or more mono- or polynuclear metal complexes. In fact, three mononuclear $(q=1)$ hydroxyl complexes $\left(\mathrm{Fe}(\mathrm{OH})_{3}^{-}, \mathrm{Fe}(\mathrm{OH})^{+}\right.$, and $\mathrm{Fe}(\mathrm{OH})_{2}$. aq) were computed by Visual MINTEQ as the most relevant for the fate of Fe(II) under our experimental conditions (Fig. Box 1B). In turns, such increment on the concentrations of Fe hydroxides seems to play a role on the decreased mobility of $\mathrm{Fe}(\mathrm{II})$ (Fig. Box 1C). Trace metals were predicted by the model to undergo similar reactions, forming mononuclear as well as polynuclear complexes (e.g. $\mathrm{Co}_{4}(\mathrm{OH})_{4}^{4+}, \mathrm{Mn}_{2}(\mathrm{OH})_{3}^{+}$, and $\left.\mathrm{Pb}_{4}(\mathrm{OH})_{4}^{4+}\right)$. As the concentrations of the trace metals hydroxides were computed to be about 15 orders of magnitude lower than $\mathrm{Fe}$ hydroxides (data not shown), most of trace metal adsorption occurred to Fe oxyhydroxides (ferrihydrite) species and organic matter. In this context, the formation of trace metal oxides might be negligible under the reducing conditions of the sediments investigated here (e.g. $\mathrm{MnO}_{4}^{-}$and $\mathrm{MnO}_{4}^{2-}$ were the most relevant oxide species with concentrations from $\sim 10^{-65}$ to $\sim 10^{-95} \mathrm{~g} \mathrm{~L}^{-1}$ ).
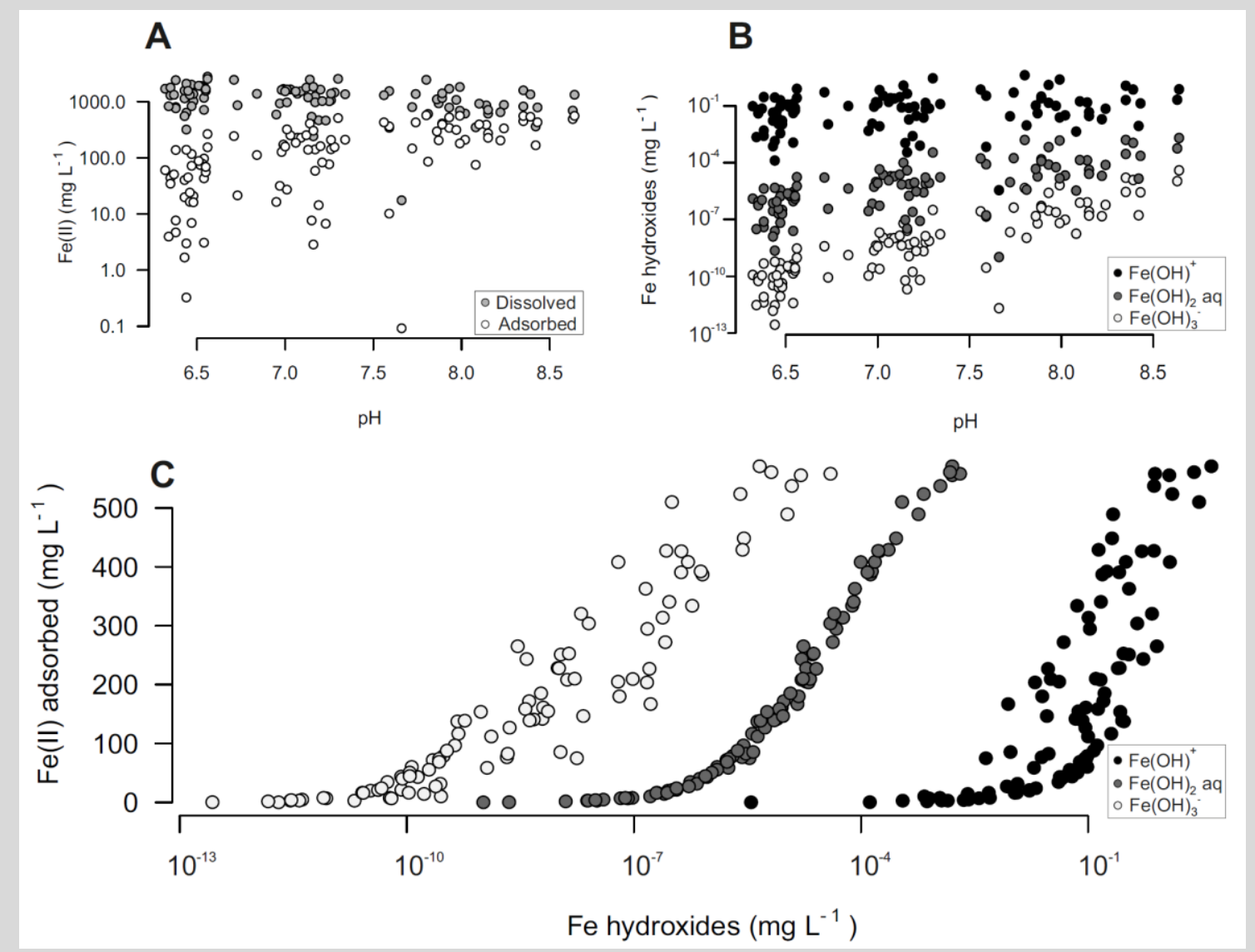

Figure Box 1: Output of Visual MinteQ for the speciation and adsorption of $\mathrm{Fe}(\mathrm{II})$ in pore waters of leachate experiments. Dissolved $\mathrm{Fe}(\mathrm{II})$ trends to decrease linearly with leachate $\mathrm{pH}$ while adsorption (A). Iron hydroxides directly increase with $\mathrm{pH}(\mathrm{B})$, concomitantly to a significant increment on $\mathrm{Fe}(\mathrm{II})$ adsorbed (C). Absolute values must be careful interpreted as some components of the systems (i.e. all active ions and adsorption sites) have not been included in the computations. Notwithstanding, general patterns and relative concentrations might hold in more realistic settings. 
Likewise, acidification (positive values of $\mathrm{pH}$ difference, Fig. 3B) of one unit of $\mathrm{pH}$ increased mobilisation by 7.3-fold (see equation on figure 3).

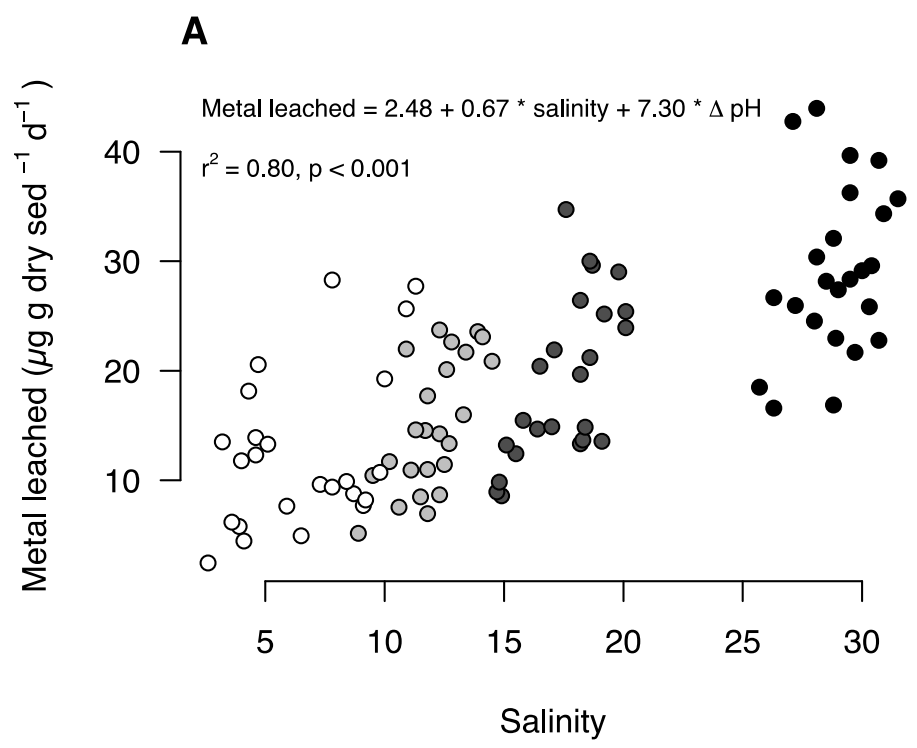

B

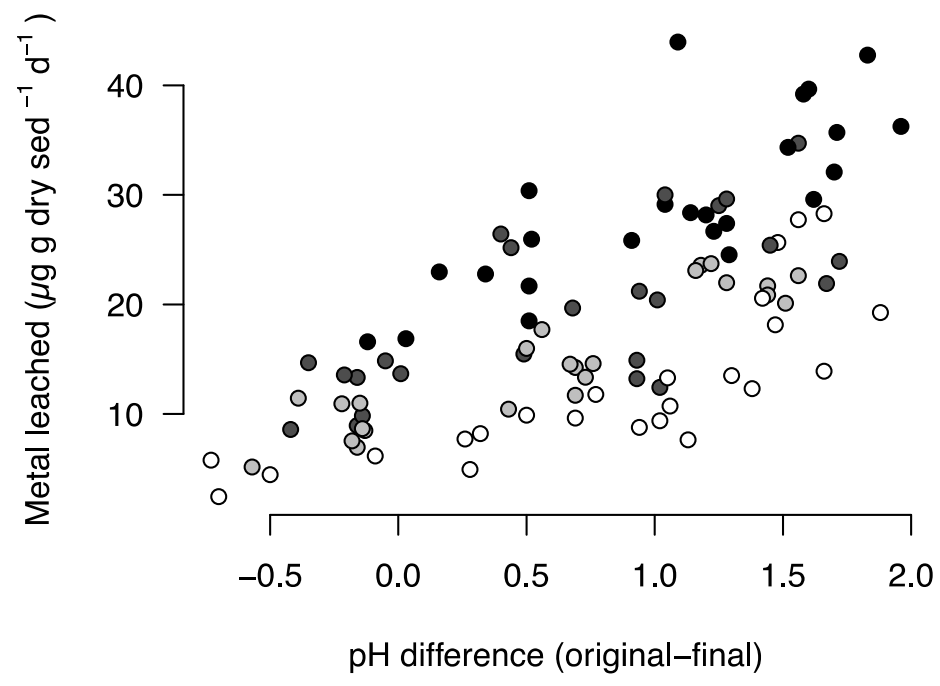

Figure 3: Effects of salinity (A) and $\mathrm{pH}$ changes (B) on the total metal mobilisation ( $\sum \mathrm{Al}, \mathrm{Co}, \mathrm{Fe}, \mathrm{Li}, \mathrm{Mn}, \mathrm{Pb}$, Sr) from sediment to the $8 \mu \mathrm{m}$ air-filtered leachate. The white, light grey, dark grey and black filled circles represent respectively $0.000 \mathrm{~g}, 0.125 \mathrm{~g}, 0.375 \mathrm{~g}$ or $0.875 \mathrm{~g}$ of marine salt added to the experimental slurry.

Interestingly, within the range of metal concentrations measured in the present study, the quantity of 
metal leached was minimally constrained by environmentally available metal concentrations (Fig. 4). For most of the metals, either no significant or very low correlation indexes $\left(r^{2}<0.1\right)$ were found between the sediment concentrations and the leached metal. In other words, the concentration of certain metals in the sediment fraction had small effects on the leachate concentrations compared to the physico-chemical mobility (i.e. empirical relationships were non significant or slopes $<<1$ on Fig. 4).

Figure 4: Effects of environmentally available metals on the mobilisation of $\mathrm{Li}(\mathrm{A}), \mathrm{Fe}(\mathrm{B})$, and $\mathrm{Pb}(\mathrm{C})$ as examples of lithogenic, diagenetically highly mobile, and anthropogenic metals, respectively. The white, light grey, dark grey and black filled circles represent respectively $0.000 \mathrm{~g}, 0.125 \mathrm{~g}, 0.375 \mathrm{~g}$ or $0.875 \mathrm{~g}$ of marine salt added to the experimental slurry.

\subsection{Mobilisation drives in situ metal concentrations in estuarine sediments}

The spatial distributions of most metals were not contiguous to the main potential sources, i.e. the Newlands or Oyster Creek docks. As exemplified for subsurface in figure 5 (A, B, C) metals levels range mostly between natural $(E F<1)$ and polluted $(E F>1)$, which confirmed the significant influence of anthropogenic sources of metals in an area where geochemistry and natural mineralogy are the main factors controlling metal fate (O’Shea 2016 https://qmro.qmul.ac.uk/xmlui/handle/123456789/12995). In fact, only low correlation values $\left(N \sim 600, r^{2}<0.15, p<0.001\right)$ were found in the present study between proximity to the landfill and metal concentration. However, environmentally available metals were not randomly distributed (Fig. 5 D, E, F). Normalised concentrations presented characteristic vertical and horizontal distributions that were significantly $(p<0.001)$ explained by geochemistry for all studied metals. The mechanisms of metal distribution and physico-chemical mobility might vary. For instance, $\mathrm{Mn}$ is diagenetically mobile, i. e. tends to be remobilised in reduced conditions at depth in the profile and precipitate near the surface (Förstner and Wittmann, 1979; Du Laing et al. 2009a, b). Pb in those sediments is believed to represent the anthropogenic influence through the peak of industrialization from late 1800s to $20^{\text {th }}$ century (O'Shea 2016 https://qmro.qmul.ac.uk/xmlui/handle/123456789/12995). Despite the potentially low mobility in soils (Li, 2006), the wide scattering of $\mathrm{Pb}$ distribution found in the currently studied estuarine sediments might also imply significant environmental mobility. Finally, $\mathrm{Sr}$ has its fate strongly determined by behaviour of $\mathrm{Ca}$ (Section 3.3). Thus, sediment chemistry was influential for all normalised metal concentrations through many mobility mechanisms (see also box 1 ). It 
cannot be discarded that additional processes (e.g. bioturbation and hydrodynamic transport) might help to explain the metal compartmentation reported here. Tidal pumping and tidal trapping are known to promote residual circulation and asymmetric flow that determine the fate of particulate material and consequentially particulate metals (Machado et al. 2016).

A

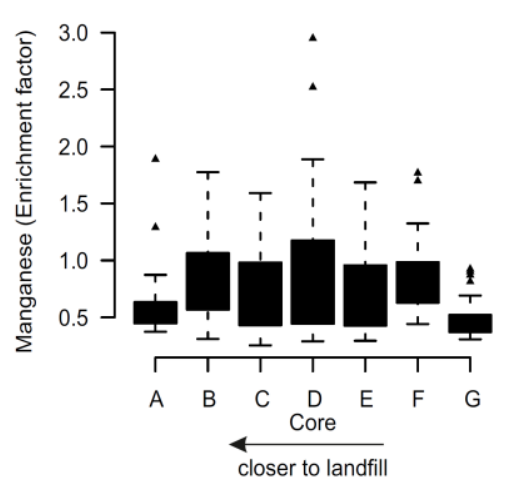

D

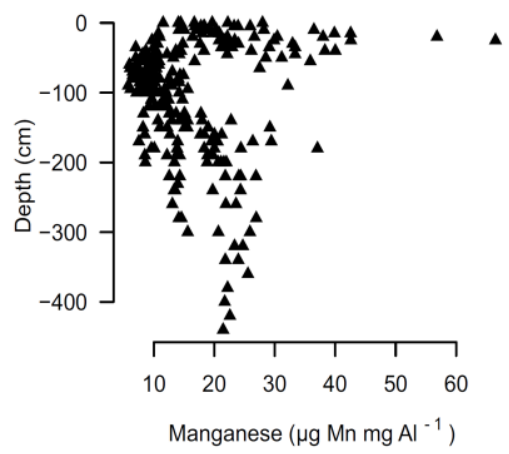

B



E

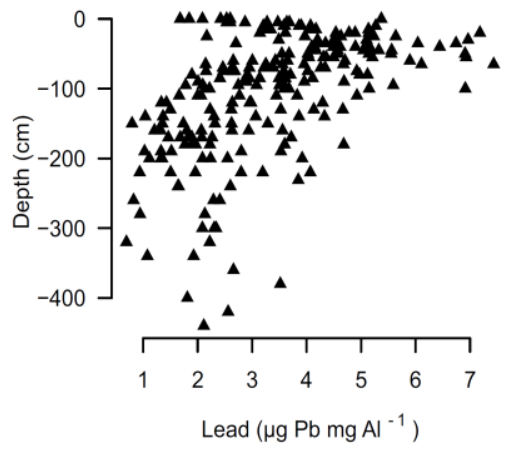

C

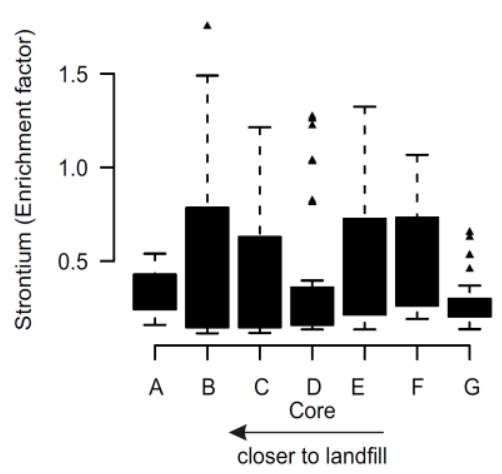

$\mathbf{F}$

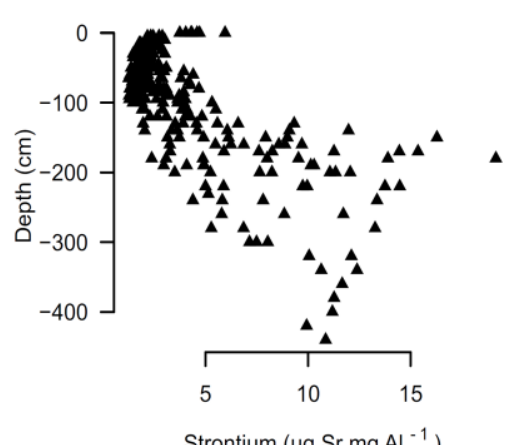

Figure 5: Environmental behaviour of selected metals on subsurface sediments. $\mathrm{Mn}$ was selected as an example of diagenetic mobility dominated by redox gradients. $\mathrm{Pb}$ was selected as it is believed as anthropogenic (O'Shea 2016 https://qmro.qmul.ac.uk/xmlui/handle/123456789/12995). Sr was selected as an example of metal mobility strongly dominated by the fate of Ca. A-C: Subsurface metal distributions displaying low contiguity to main potential metal contamination source (upper and lower limits of boxes represent respectively $75 \%$ and $25 \%$ quartiles, bar limits represent $99 \%$ and $1 \%$ quartiles, small triangles are extreme values). D-F: Metal distributions displaying high dependence of geochemical gradients (triangles represent individual measured data). 


\subsection{Sediment geochemistry and pollution levels}

This section shows selected examples of metals with representative effects of geochemistry on their pollution levels (either increasing or decreasing). Generally, the patterns of surface and vertical concentrations of $\mathrm{Cu}, \mathrm{Co}, \mathrm{Zn}$ and $\mathrm{Pb}$ are similar (see supplementary figure B. 2 for major ion influence). Also, Fe and Mn presented similar behaviour. Enrichment factor of Fe and $\mathrm{Mn}$ were correlated to most of the trace metals $(p<0.01)$ in surface and relationships commonly faded with increasing depth (data not shown). Sr and $\mathrm{Cr}$ presented peculiar behaviour as discussed later.

Surface metal levels in the intertidal area were strongly influenced by $\mathrm{pH}$ and organic matter content $\mathrm{p}<$ 0.001). The latter was positively correlated to water content and metal concentrations in the sediment (Fig. 6). It suggests that intertidal sediments flooded more frequently or for longer periods might present higher organic matter content, which provided important ligands for metal immobilisation. It has been noticed that increased flooding generally enhances organic matter content in sediments due to less optimal degradation conditions (Du Laing et al. 2009b). Nevertheless, the effect of organic matter on the concentration of trace metals might be ignored in environmental health assessment of metal pollution if normalisation of metal concentration is based exclusively on sediment granulometry of mineral phases. Organic matter must be taken into account when assessing metal contamination in intertidal areas. Du Laing et al. (2009a) found that a $25 \%$ increment in organic matter might result in 200 -fold increase in metal concentrations. In the present results, enrichment factors show a more modest sensitivity to organic content. Notwithstanding, metal immobilisation by organic matter was noteworthy and ignoring it might further contribute to hamper identification on the reason of metal accumulation in estuarine sediments and lead to false positive indication of presence of anthropogenic sources.

The figure $6(B, C)$ exemplifies the effect of organic matter on the environmental levels of a potentially anthropogenic trace metal (Co) and a lithogenic redox sensitive metal ( $\mathrm{Fe})$. In turn, $\mathrm{Fe}$ 
influences the concentration of many trace metal through precipitation and co-precipitation during the formation of oxy-hydroxide iron colloids (Fairbrother et al. 2007; Du Laing et al. 2009c). Therefore, a synergistic effect on organic matter and redox cycling metals (as Fe and $\mathrm{Mn}$ ) on the immobilisation of trace metals cannot be discarded. 

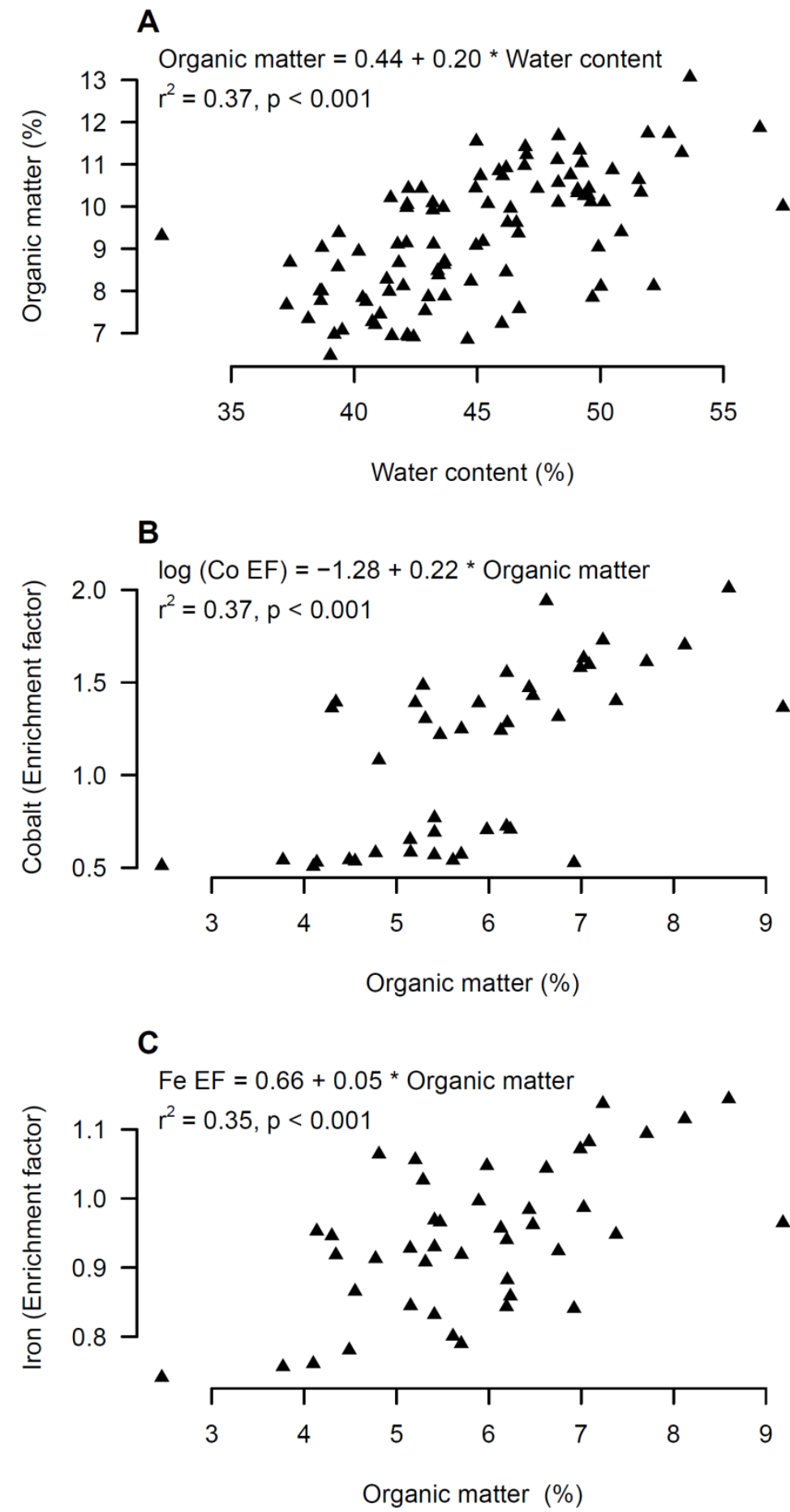

Figure 6: Environmental behaviour of organic matter and selected metals on surface sediments. A: organic matter increases with water content. B: Relationship of cobalt and organic matter. C: Relationship of iron and organic matter. Empirical relationships reported here might explain $35-37 \%$ of metal enrichment factors (see fitting equations). 
In the figure $6 \mathrm{~B}$ it is also possible to distinguish two clusters of data on the relationship between organic matter and $\mathrm{Co}$, which were also observed for $\mathrm{Cu}, \mathrm{Pb}, \mathrm{Cr}$ and $\mathrm{Zn}$. The upper cluster ( $\mathrm{EF}>1$ ) represent the samples taken from the intertidal areas facing the main channel to the Thames Estuary (transects 1-5, Fig. 1), in which $\mathrm{pH}$ of the sediment was higher. While the lower cluster of data (Fig. $6 \mathrm{~B}, \mathrm{EF}<1$ ) are sampling points under the influence of Oyster Creek (transects 6-12), where a drop of approximately a unit of pH was observed. From the current results it is impossible to speculate whether the changes on $\mathrm{pH}$ are purely natural or have an anthropogenic influence. The gradient on sediment $\mathrm{pH}$ clearly influenced the metal behaviour in sediment surface samples. Enrichment factors smaller than 1 were observed for most of metal in the area of potentially higher contamination (e.g. under influence of the Newlands, adjacent docks, and with more enclosed hydrodynamic). In fact, the surface level metal concentrations considered in the present study ( $\Sigma \mathrm{Al}, \mathrm{Co}, \mathrm{Cr}, \mathrm{Cu}, \mathrm{Fe}, \mathrm{Li}, \mathrm{Mn}, \mathrm{Ni}, \mathrm{Pb}, \mathrm{Sr}, \mathrm{Zn}$ ) could be also described as function of sediment $\mathrm{pH}$ $\left(r^{2}=0.46, p<0.001 ;\right.$ Supplementary material B. 3), which exemplifies the decisive effect of surface sediment $\mathrm{pH}$ on environmental metal levels.

The effect of $\mathrm{pH}$ was not consistent throughout the sediment profile. Despite the strong correlation on the surface, subsurface sediments presented weaker or even reverse relationship with pH (Fig. 7 A-B). This ambiguous effect of $\mathrm{pH}$ on metal concentrations on surface and subsurface reflect the different processes taking place at these two compartments. Surface sediments (top $5 \mathrm{~cm}$ layer) are successively exposed to air and water. Metal solubilized by lower $\mathrm{pH}$ values on the surface sediments can be easily transferred to the water column and removed from the intertidal area within a tidal cycle (Machado et al, 2016). Thus, $\mathrm{pH}-$ driven mobilisation in the surface sediments imply decreasing levels of metals. On the other hand, metals solubilized in the subsurface sediments move much slower. Maximum advection of water within sediment layers is of order of $10^{-6} \mathrm{~m} \mathrm{~s}^{-1}$ (Brand et al. 2013). Therefore, the $\mathrm{pH}$-driven mobilisation in subsurface might instead transport metals to places of preferential accumulation, where interaction with strong metal immobilisers (e.g. sulphide) could actually increase metal levels. 
Moreover, subsurface sediments undergo several diagenetic processes that also affect the metal fate. For instance, $\mathrm{Sr}$ distribution is strongly determined by the fate of $\mathrm{Ca}$ (Fig. 7C). As an alkali Earth metal, $\mathrm{Sr}$ presents high affinity for carbonates (in which it can readily replace Ca) (Lerouge et al. 2010; O'Shea 2016 https://qmro.qmul.ac.uk/xmlui/handle/123456789/12995). Therefore, a decrease of $\mathrm{pH}$ in the sediment profile would cause decalcification, with consequent dissolution of carbonates and release of both $\mathrm{Ca}$ and Sr (Du Laing et al. 2009b). The relationship between Sr enrichment factors and Ca was also present in the surface but with smaller explanatory power $\left(r^{2}=0.53, p<0.001\right)$. A stronger correlation at depth was also observed for $\mathrm{Mg}, \mathrm{Na}, \mathrm{K}$ and many trace metal enrichment factors (supplementary material $\mathrm{B}$. 2), suggesting that diagenetic provisioning of adsorption/ co-precipitation sites, and the interaction with sea water ions might have a predominant role on the mobility of metals within the subsurface sedimentary layers.

Such influence of major cations (i.e. alkaline and alkali Earth metals) on the behaviour of trace metals was weaker at the surface. The only evident exception was the relationship between Al and K (Fig. 7D). Geochemically normalized Al concentrations significantly $(p<0.001)$ decreased with the increment of K concentrations. Likewise, geochemically normalised concentrations of Li increased proportionally to $\mathrm{K}$ concentrations $(p<0.001)$ since it presented exactly the opposite surface fate as Al. Regarding metal pollution levels, the presence of major cations might be considered influential at the sediment surface and determining at subsurface with an explanatory power between $19 \%$ to $97 \%$ (see fitting equations on Fig. 7). 
A

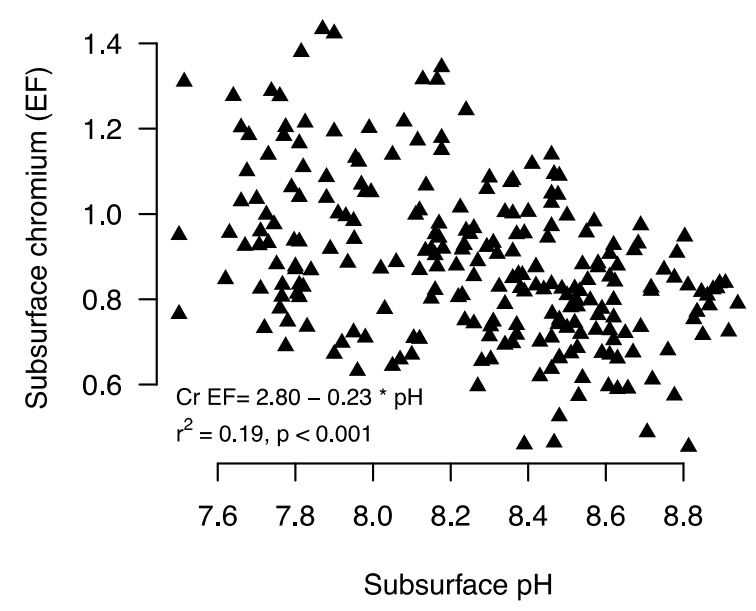

C

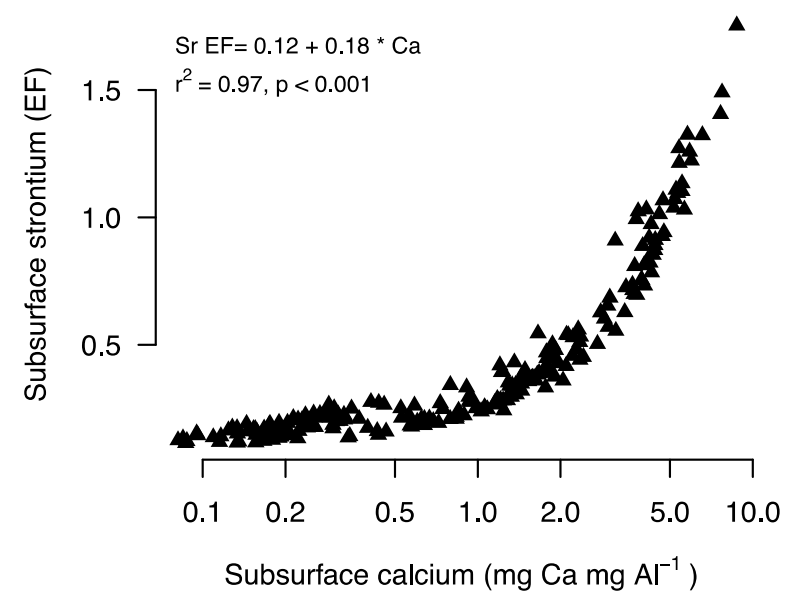

B

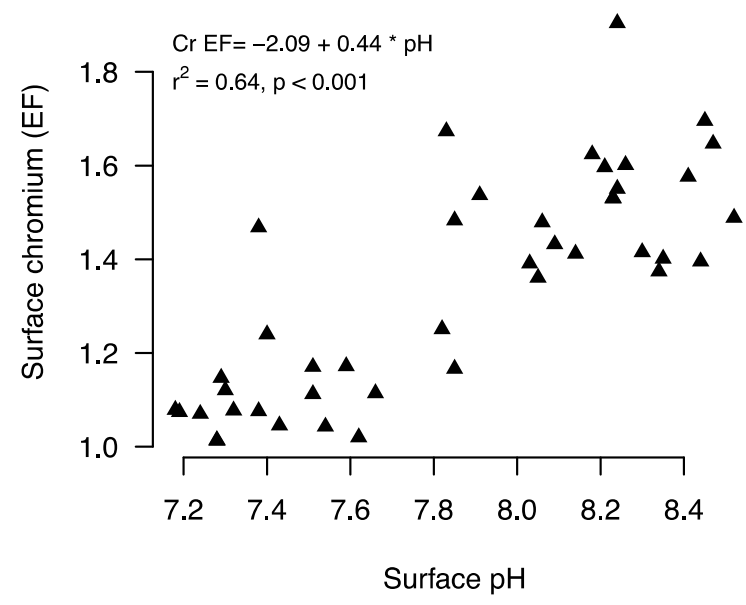

D

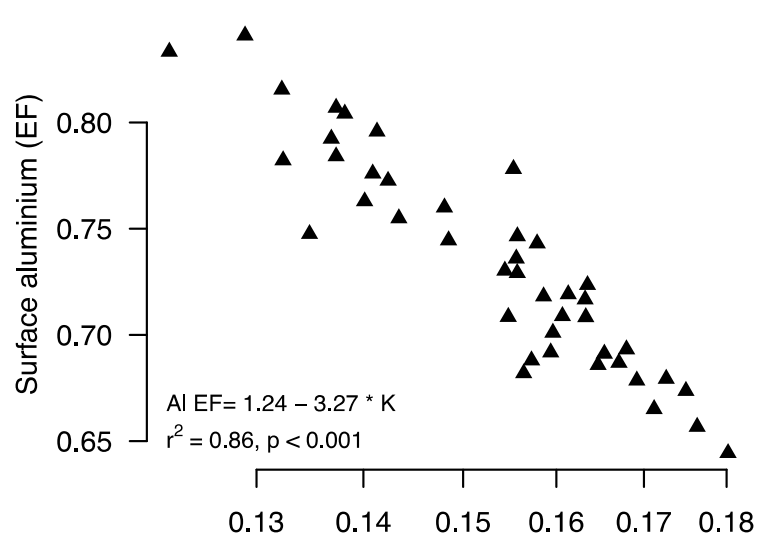

Surface potassium (mg K mg $\mathrm{Al}^{-1}$ )

Figure 7: Geochemistry determining pollution levels, in terms of enrichment factors (EF), of trace metals on both surface and subsurface sediments. Chromium is differently influenced by $\mathrm{pH}$ in subsurface $(\mathrm{A})$ and surface (B) sediments. Precipitation and co-precipitation (C) and negative interaction (D) with major cations influences Sr and Al levels, respectively.

Altogether, the results from the field assessment of metal levels also suggest that sediment geochemistry determines contamination levels of most of the metals in this tidal flat and partially accounts for the complex contaminant signatures. The most geochemical influential parameters at surface were $\mathrm{pH}$ and organic matter content, followed by major cations and Fe-Mn. In subsurface, the diagenetic processes and slower advection favoured the higher influence of major cations on metal concentrations. 


\subsection{High metal mobility in situ in estuarine sediments}

Intertidal estuarine sediments might present high spatial chemical heterogeneity where metal levels are homogeneously controlled by biogeochemical processes (Mouret et al. 2016). Among those processes, the exchange of Fe between water and intertidal sediments is suggested as a vitally important mechanism of metal flux (Johnston et al. 2011). The results presented here from laboratory leachate experiments and field assessments of geochemical influence on metal levels suggest that potentially high metal mobilisation might occur within contaminated estuarine sediments. Applying the $\mathrm{pH}$ of the surface sediments from the saltmarsh studied here on the equation presented in Figure 2 it was possible to confirm that mobilisation is the key factor for metal concentrations in sediments despite the strong anthropogenic influence in this tidal marsh (Fig. 8 A-B). Fe enrichment factors were higher in the tidal flats, away from the potential main anthropogenic sources (Fig. 8B). As mentioned earlier, several trace metals presented similar patterns. Instead denoting absence of impacts, the low enrichment factors of several metals in the area of Oyster Creek denounce the $\sim 1000$-fold higher metal mobilisation in that area. In other words, it means that the most human-impacted area is exporting significant amounts of metals to the adjacent waters. In the case of $\mathrm{Fe}(\mathrm{II})$ the main driver of mobility was the gradient of sediment $\mathrm{pH}$ (Fig. 8A). Mobilisation of Fe(II) also explains $39 \%$ of the observed pollution levels of other metals and more anthropogenic metals (Supplementary figure B. 3). Indeed, it has been extensively demonstrated that Fe behaviour correlates with the fate of other metals (Fairbrother et al. 2007; Machado et al. 2016; Prajith et al. 2016). The geochemical explanations for such effects are presented in box 1 . Nonetheless, given the current results from the laboratory experiments, salinity might also play an important role in explaining part of the remaining variability for the other metals. 


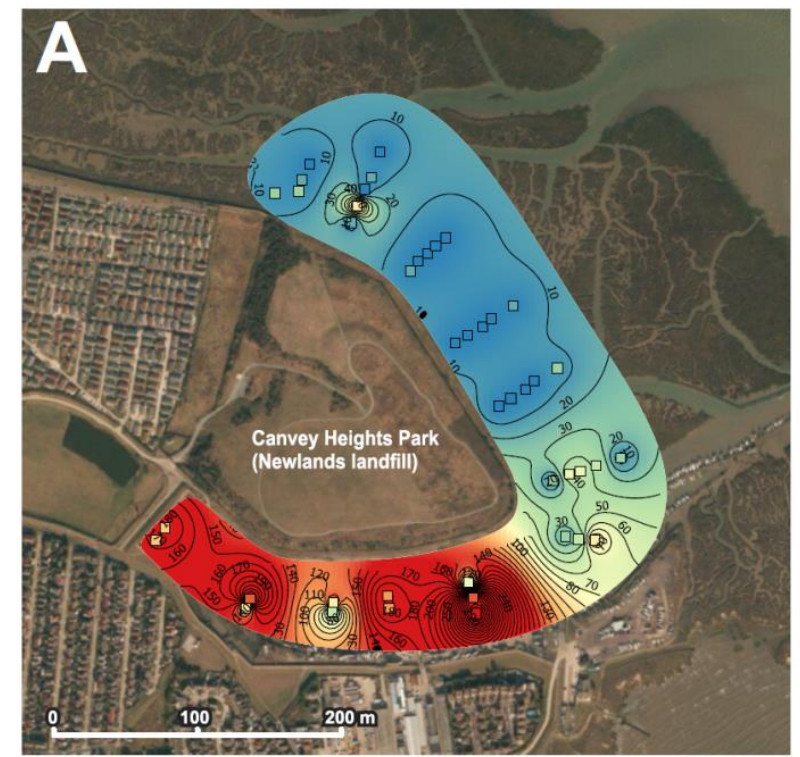

Mobilisation $\left(\mu \mathrm{g} \mathrm{g}\right.$ dry $\left.\operatorname{sed}^{-1} \mathrm{~d}^{-1}\right)$

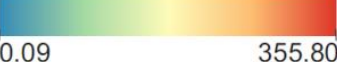

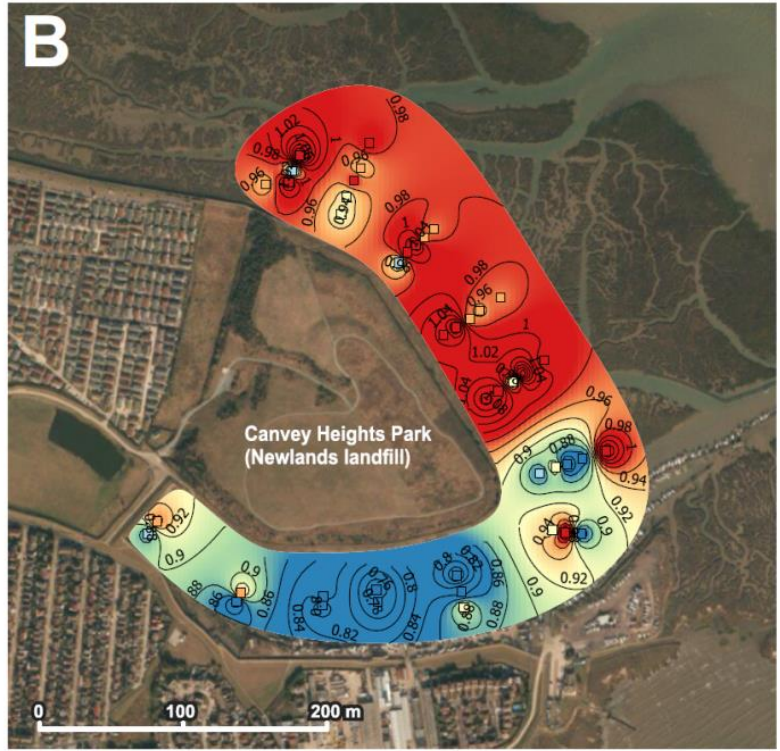

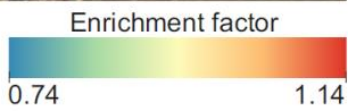

Figure 8: Effect of metal mobility on pollution levels. Iron mobilisation (panel A, $\mu \mathrm{g} F\left(\right.$ II) $g$ dry sed ${ }^{-1} d^{-1}$ ) was negatively correlated to iron enrichment factor (panel B) in the sediment surface $\left(r^{2}=0.42, p<0.001\right)$. In both panels, squares represent measured points and the colour scale for their values is presented in the graph. The contour lines are presented for the interpolated values in the whole study area.

\section{Conclusions and future directions}

In a recent study, O'Shea (2016) found that a historical leachate plume from Newlands Landfill resulted in elevated sediment metal concentrations. This zone of enrichment only extended to ca. $20 \mathrm{~m}$ from the landfill edge as a result of the effective natural attenuation by the fine-grained sediment and/or post depositional mobility. Therefore, as in many estuaries, beyond this enrichment zone, metal levels were moderately high but without spatial continuity to the main anthropogenic source. Our results demonstrate that the observed impacted zone may have been much larger because sediment geochemical gradients affected metal mobility and pollution levels for all studied metals. Metal mobility was found to potentially transfer significant amounts of metals from sediments to the aqueous phase in the laboratory. In the field, 
gradients of $\mathrm{pH}$ and organic matter at the sediment surface were the most important for most of the metals, while major cations were decisive in the subsurface.

The significant observed effects of salinization and acidification on the mobility of metals have implications in terms of global change impacts on industrialized estuaries. Sea-level rise might cause salinization in many coastal systems such as the Thames Estuary, which faces about $9 \mathrm{~mm}$ year ${ }^{-1}$ sea-level rise (last 20 years, Environment Agency data) associated to a projected decrease in annual precipitation (Johnson et al. 2009). Additionally, sea-level rise will increase the frequency of flooding, therefore increasing the content of organic matter in the sediments (see section 3.3) and consequently affecting the $\mathrm{pH}$. For instance, Du Laing et al. (2009b) found that decomposition of organic matter in sediments released $\mathrm{CO}_{2}$ that accounted for the acidification and mobilisation of $\mathrm{Ca}, \mathrm{Fe}, \mathrm{Mn}$, and $\mathrm{Ni}$ at low sulphide concentrations. This remobilisation of metals might be especially concerning for many industrialized countries, in which tons of metal contaminated material were disposed in coastal environments. For instance, between 1976 and 1977 about 9,000 tons of metals $(\Sigma \mathrm{Cd}, \mathrm{Cr}, \mathrm{Cu}, \mathrm{Hg}, \mathrm{Pb}$, and $\mathrm{Zn})$ were dumped in British estuarine and coastal systems (Förstner and Wittmann, 1979). Like at Newlands, most of these landfills relied on environmental natural attenuation of the pollution plumes. In fact, a recent review found $>1200$ coastal landfills at risk of flooding and/or erosion only in England and Wales (Brand et al. 2017). The remobilisation of sedimentimmobilised metals increases the potential for biological impacts. In estuarine water, metals may present high bioavailability, and are subjected to long environmental persistence driven by hydrodynamic and geochemical processes (Machado et al. 2016). Therefore, the risk of remobilisation of contaminants from historic contaminated estuarine sediments might contribute to exacerbate pollution and habitat loss in a context of global changes.

The comparison of the leachate empirical regression with environmental levels ratifies that metal mobilisation is an important variable that explains for at least $\sim 40 \%$ the pollution levels in estuarine tidal sediments. Further studies are required to verify whether the empirical models for mobilisation provided here are valid for other estuaries in order to derive a method to isolate the effect of metal 
mobility and allow inference of the real impact anthropogenic sources of metal contamination in estuarine environments.

\section{Acknowledgements}

Abel Machado carried out this research within the Erasmus Mundus Joint Doctorate Program SMART (Science for MAnagement of Rivers and their Tidal systems) funded with the support of the EACEA of the European Union. Francis O'Shea performed the collection and chemical analyses of field data as part of his Natural Environment Research Council CASE studentship (Grant number NE/I018212/1) in association with Arcadis N.V. All laboratory and field work was carried out within the School of Geography Queen Mary University of London.

\section{References}

Attrill, M.J., Thomes M. 1995. Heavy metal concentrations in sediments from the Thames Estuary, UK. Marine pollution Bulletin. 30, 742-744.

Brand, A., Lewandowski, J., Hamann, E., Nützmann, G. 2013. Advection around ventilated U-shaped burrows: A model study. Water Res. 49, 2907-2917.

Brand, J.H., Spencer, K.L., O'Shea, F.T. and Lindsay, J.E. 2017. The potential ecological and human health risks of historic landfills on low-lying coasts and estuaries. WIREs Water 2017, e1264. doi:

10.1002/wat2.1264

Bianchi, T.S. 2007. Biogeochemistry of Estuaries. Oxford University Press, New York.

Bryan, G.W., Langston, W.J. 1992. Bioavailability, accumulation and effects of heavy metals in sediments with special reference to United Kingdom estuaries: a review. Environ. Pollut. 74, 89-131. 
Caulmert Limited. 2011a. Hadleigh Sea Wall Landfill Site. Essex County Council, Annual Monitoring Report.

Caulmert Limited. 2011b. Newlands Landfill, Annual Monitoring Report, Bangor, Caulmert Limited.

Chapman, P.M., Wang, F. 2001. Assessing sediment contamination in estuaries. Environ. Tox. Chem. 20, 322.

Chen, M., Ma, L.Q. 2001. Comparison of Three Aqua Regia Digestion Methods for Twenty Florida Soils. Soil Sci. Soc. Am. J. 65, 491-499.

Craft, C.B., Seneca, E.D., Broome, S.W. 1991. Loss on ignition and kjeldahl digestion for estimating organic carbon and total nitrogen in estuarine marsh soils: Calibration with dry combustion. Estuaries, 14: 175-179.

Du Laing, G., Meers, E., Dewispelaere, M., Vandescasteele, B., Rinklebe, J., Tack, F.M.G., Verloo, M.G. 2009a. Heavy metal mobility in intertidal sediments of the Scheldt estuary: field monitoring. Sci. Total. Environ. 407, 2909-2930.

Du Laing, G., Meers, E., Dewispelaere, M., Rinklebe, J., Vandescasteele, B., Verloo, M.G., Tack, F.M.G. 2009b. Effect of water table level on metal mobility at different depth in wetland soils of the Scheldt estuary (Belgium). Water Air Soil Pollut. 202, 353-357.

Du Laing, G., Rinklebe, J., Vandescasteele, B., Meers, E., Tack, F.M.G. 2009c. Trace metal behavior in estuarine and riverine floodplain soil and sediments: a review. Sci. Total. Environ. 407, 3972-3985.

Fairbrother, A., Wenstel, R., Sappington, K., Wood, W. 2007. Framework for metals risk assessment. Ecotoxicol. Environ. Saf. 68, 145-227.

Förstner, U., Wittmann, G.T.W. 1979. Metal pollution in the Aquatic Environment. Springer-Verlag, Berlin Heidelberg New York.

Greger, M., Kautsky, L., Sandberg, T. 1995. A tentative model of Cd uptake in the Potamogeton pectinatus in relation to salinity. Environ. Exp. Bot. 35, 215-225. 
Hietanen, S., Sillén, L.G. 1954. Studies on the hydrolysis of metal ions. Acta. Chemica Scandinavica 8: 16071625.

Johnson, A.C., Acreman, M.C., Bunbar, M.J., Feist, S.W., Giacomello, A.M., Gozlan, R.E., Hinsley, S.A., Ibbotson, A.T., Jarvie, H,P, Jones, J.I., Longshaw, M., Maberly, S.C., Marsh, T.J., Neal, C., Newman, J.R., Nunn, M.A., Pickup, R.W., Reynard, N.S., Sullivan, C.A., Sumpter, J.P., Williams, R.J. 2009. The British river of the future: How climate change and human activity might affect two contrasting river ecosystems in England. Sci. Total Environ. 407, 4787-4798.

Johnston, S.G., Keene, A.F., Bush, R.T., Sullivan, L.A., Wong, V.N.L. 2011. Tidally driven water column hydrogeochemistry in a remediating acidic wetland. J Hydrol. 409, 128-139.

Jowsey, P.C. 1966. An Improved Peat Sampler. New Phytologist. 65, 245-248.

Kennish, M.J. 1991. Ecology of Estuaries: Anthropogenic Effects. CRC Press, Florida.

Kersten, M., Smedes, F. 2002. Normalisation procedures for sediment contaminants in spatial and temporal trend monitoring. J. Environ. Monit. 4, 109-115.

Lee, G.F., Stumm, W. Determination of ferrous iron in the presence of ferric iron with bathophenanthroline. Journal American Water Works Association. 52, 1567-1574.

Lerouge, C., Gaucher, E.C., Tournassat, C., Negrel, P., Crouzet, C., Guerrot, C., Gautier, A., Michel, P., Vinsot, A., Buscchaert, S. 2010. Strontium distribution and origins in a natural clayey formation (CallovianOxfordian, Paris Basin, France): A new sequential extraction procedure. Geochim. Cosmochim. Ac. 74, 2926-2942.

Li, L.Y. 2006. Retention capacity and environmental mobility of Pb in soils along highway corridor. Water Air Soil Poll. 170, 211-227.

Machado, A.A.S., Spencer, K., Kloas, W., Tofollon, M., Zarfl, C. 2016. Metal fate and effects in estuaries: A 
review and conceptual model for better understanding of toxicity. Sci. Total Environ. 541, 268-281.

O'Shea, F.T. 2016. Assessment of diffuse pollution originating from estuarine historical landfills. PhD Thesis, Queen Mary University of London, https://qmro.qmul.ac.uk/xmlui/handle/123456789/12995

Millennium Ecosystem Assessment. 2005. Ecosystems and Human Well-being: Wetlands and Water Systhesis. World Resources Institue, Washington, DC. USA.

Mouret, A., Anschutz, P., Deflandre, B., Deborde, J., Canton, M., Poirier, D., Grémare, A., Howa, H. 2016. Spatial heterogeneity of benthic biogeochemistry in two contrasted marine environments (Arcachon Bay and Bay of Biscay, SW France). Estuarine, Coastal and Shelf Science 179, 51-65.

National Water Research Institute. 2001. Recoverable and leachable elements in SUD-1. National Water Research Institute. Burlington, ON, Canada.

Prajith, A., Purnachandra Rao, V., Chakraborty, P. 2016. Distribution, provenance and early diagenesis of major and trace metals in sediment cores from the Mandovi estuary, western India. Estuar. Coast. Shelf S. 2016. 170, 173-185.

R Core Team. R: a language and environment for statistical computing. R Foundation for Statistical Computing, Vienna. http://www.R-project.org/. (Accessed 9 Nov 2013).

Ridgway, J., Shimmield, G. 2002. Estuaries as repositories of historical contamination and their impacts on shelf seas. Estuar. Coast. Shelf S. 55, 903-928.

Sachs, L. Angewandte Statistik; Springer: Berlin, 1997.

Shepard, F.P. 1954. Nomenclature based on sand-silt-clay ratios. J Sed. Petrol. 5,24.

Schneider, L., Maher, W.A., Floyd, J., Potts, J., Batley, G.E., Gruber, B. 2016. Transport and fate of metal contamination in estuaries: Using a model network to predict the contributions of physical and chemical factors. Chemosphere 153, 227-236. 
Spencer, K.L., MacLeod, C.L. 2002. Distribution and partitioning of heavy metals in estuarine sediment cores and implications for the use of sediment quality standards. Hydrol. Earth Syst. 6, 989-998.

Spencer, K.L., O'Shea, F.T. 2014. The hidden threat of historical landfills on eroding and low-lying coasts. ECSA Bull. 63, 16-17.

Unesco/ICES/SCOR/IAPSO. 1981. Background papers and supporting data on the Practical Salinity Scale 1978. Unesco technical papers in marine science. Unesco, Paris- France.

van der Wal, D., Pye, K. 2004. Patterns, rates and possible causes of saltmarsh erosion in the Greater Thames area (UK). Geomorphology. 61, 373-391.

Vane, C.H., Beriro, D.J., Turner, G.H. 2015. Rise and fall of mercury (Hg) pollution in sediment cores of the Thames Estuary, London, UK. Earth Env. Sci. T. R. So. 105, 285-296.

Zhang, J. Liu, C.L. 2002. Riverine composition and estuarine geochemistry of particulate metals in ChinaWeathering features, anthropogenic impacts and chemical fluxes. Estuar. Coast. Shelf S. 54, 1051-1070.

Zwolsman, J.J.G., Berger, G.W., Van Eck, G.T.M. 1993. Sediment accumulation rates, historical input, postdepositional mobility and retention of major element and trace metals in salt march sediment of Scheldt estuary. SW Mar. Chem. 44, 73-94. 


\section{SUPPLEMENTARY INFORMATION}

Machado, A.A.S., Spencer, K., Zarfl, C., O’Shea, F.2017. Unravelling metal mobilisation under complex contaminant signatures. Science of the Total Environment.

Contact: machado@igb-berlin.de

Important dataset: The current work advances the research on estuarine metal pollution starting from the original dataset of O'Shea, 2016. Part of this primary data is currently submitted for peer-review and might be publically available soon. Therefore, readers interested on further information on methods as well as on the spatial distribution of metals in the studied area are encouraged to search for the publication entitled "The contaminant legacy from historic coastal landfills and their potential as sources of diffuse pollution" by O'Shea, F.T., Spencer, K., and Cundy, A.B.

Supplementary Material A: Material and Methods

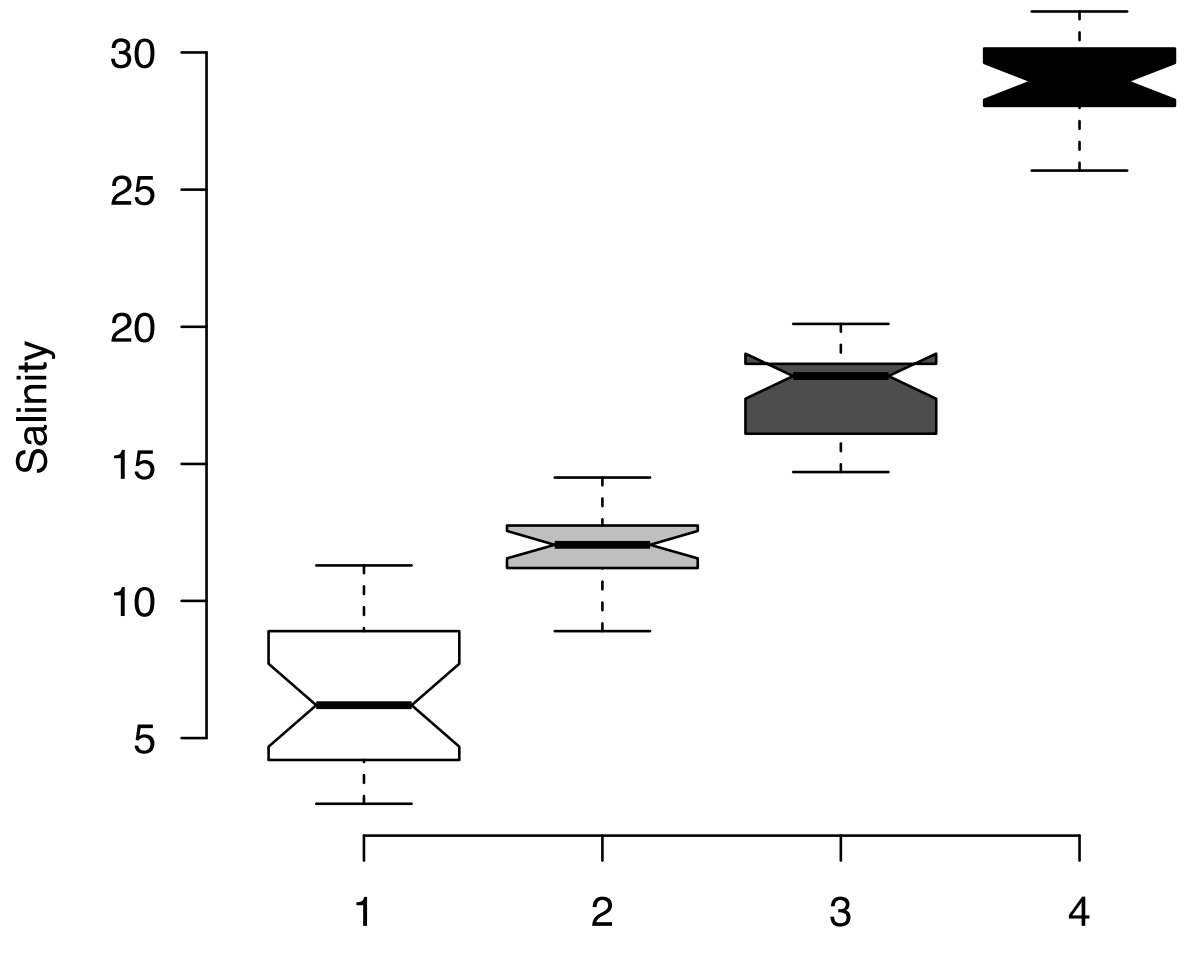

Salt treatement

Figure A. 1: Effect of marine salt addition on the salinity of the leachate (treatments 1, 2, 3, and 4 represent 
respectively addition of $0.000 \mathrm{~g}, 0.125 \mathrm{~g}, 0.375 \mathrm{~g}$ or $0.875 \mathrm{~g}$ of marine salt (Sigma Aldrich) to the experimental slurry).

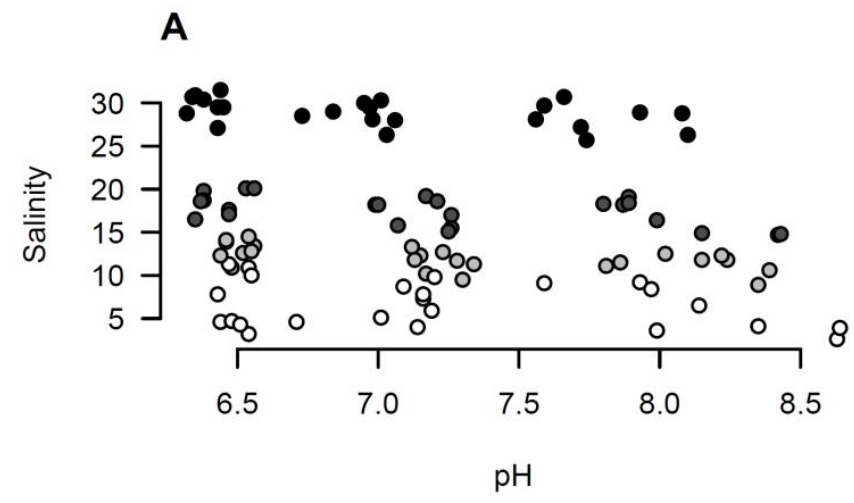

B

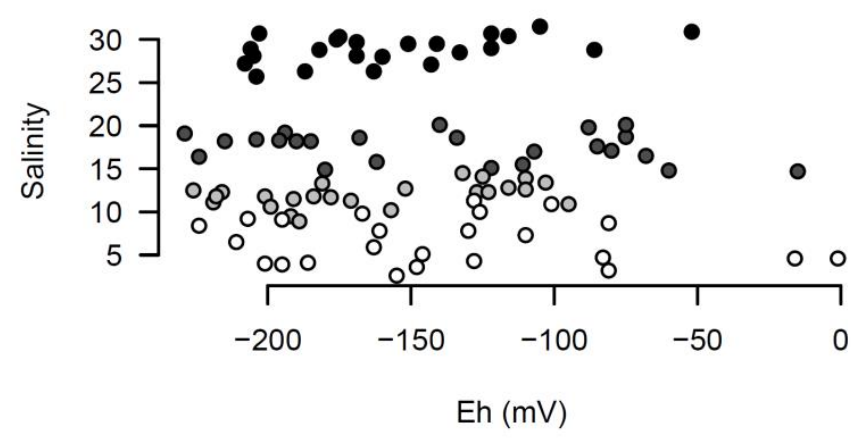

C

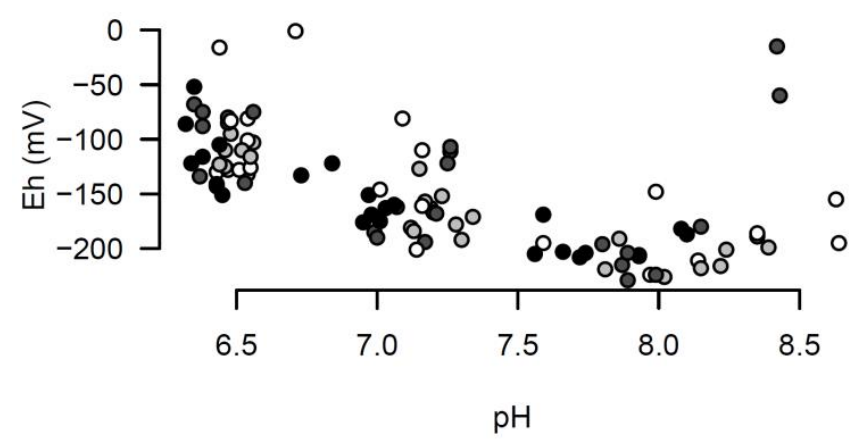

Figure A. 2: Multi-variate experimental design of salinity-pH (A), and salinity-redox potential (B), and covariation of $\mathrm{pH}$-redox potential (C). The white, light grey, dark grey and black filled circles represent 
respectively $0.000 \mathrm{~g}, 0.125 \mathrm{~g}, 0.375 \mathrm{~g}$ or $0.875 \mathrm{~g}$ of marine salt added to the experimental slurry.

Table A. 1: Major electrolytes in artificial sea salt used on leachate experiments.

\begin{tabular}{cc}
\hline Component & Concentration $\left(\mathrm{mg} \mathrm{L}^{-1}\right)^{\mathrm{a}}$ \\
\cline { 2 - 2 } Chloride & 19290 \\
Sodium & 10780 \\
Sulfate & 2660 \\
Potassium & 420 \\
Calcium & 400 \\
Bicarbonate & 200 \\
Strontium & 8.8 \\
Boron & 5.6 \\
Bromide & 56 \\
lodide & 0.24 \\
Lithium & 0.3 \\
Fluoride & 1.0 \\
Magnesium & 1320 \\
Other trace & \\
elements & $<0.5$ \\
& \\
\hline \hline & \\
\hline Values provided by Sigma Aldricht for the concentration of $38 \mathrm{~g}$ Salt $\mathrm{L}^{-1}$
\end{tabular}

Table A. 2: Major metals measured in the artificial salt water used on leachate experiments.

\begin{tabular}{ccccc}
\hline \hline \multirow{2}{*}{ Salinity } & \multicolumn{4}{c}{ Metals $\left(\mathrm{mg} \mathrm{L}^{-1}\right)$} \\
\cline { 2 - 5 } & $\mathrm{Ca}$ & $\mathrm{K}$ & $\mathrm{Mg}$ & $\mathrm{Na}$ \\
0 & $164.13 \pm 0.99$ & $0.09 \pm 0.03$ & $18.83 \pm 0.05$ & $24.80 \pm 0.29$ \\
5 & $156.57 \pm 1.11$ & $35.62 \pm 2.55$ & $215.19 \pm 8.53$ & $865.43 \pm 16.91$ \\
15 & $152.34 \pm 0.81$ & $158.05 \pm 9.97$ & $524.68 \pm 4.65$ & $2596.29 \pm 50.72^{\mathrm{a}}$ \\
30 & $277.89 \pm 1.61$ & $438.95 \pm 13.15$ & $1203.02 \pm 14.40$ & $7788.86 \pm 152.16^{\mathrm{a}}$ \\
& & & & \\
\hline \hline
\end{tabular}

${ }^{a}$ Values estimated out of calibration range.

There was an effect of salinity on quantification of $\mathrm{Li}, \mathrm{Mn}$ and $\mathrm{Sr}$. This effect was discounted from each sample by decreased the value returned by a linear regression of measured salinity and 
metal concentration on blanks (table A. 3). Laboratory standards were analysed every 10 samples (quantification limits and analytical quality parameters on supplementary table A. 4).

Table A. 3: Saltwater interference on the trace metal ICP quantification.

\begin{tabular}{cccc}
\hline \hline Salinity & \multicolumn{3}{c}{ Metal $\left(\mu \mathrm{g} \mathrm{L}^{-1}\right)$} \\
\cline { 2 - 4 } & $\mathrm{Li}$ & $\mathrm{Mn}$ & $\mathrm{Sr}$ \\
& & & \\
0 & $\mathrm{BQL}^{\mathrm{b}}$ & $\mathrm{BQL}^{\mathrm{b}}$ & $\mathrm{BQL}^{\mathrm{b}}$ \\
5 & $31.12 \pm 0.08$ & $\mathrm{BQL}^{\mathrm{b}}$ & $761.52 \pm 2.16$ \\
15 & $90.24 \pm 0.05$ & $6.80 \pm 0.01$ & $1962.58 \pm 1.39$ \\
30 & $207.71 \pm 0.13$ & $13.35 \pm 0.01$ & $3799.88 \pm 5.46$ \\
& & & \\
\hline \hline
\end{tabular}

${ }^{a}$ All the other metals discussed in the present work were below quantification limits in all the artificial salt water.

${ }^{\mathrm{b}}$ Below quantification limits.

Table A. 4: Quantification limit and quality parameters for trace metal analysis $(\mathrm{N}=5)$.

\begin{tabular}{cccc}
\hline \hline Metal & Quantification limit $\left(\mu \mathrm{g} \mathrm{L}^{-1}\right)^{\mathrm{a}}$ & Accuracy $(\%)$ & Precision (\%) \\
\cline { 2 - 4 } $\mathrm{Al}$ & & & \\
$\mathrm{Cd}$ & 40.00 & 93.7 & 14.4 \\
$\mathrm{Co}$ & 20.00 & 96.3 & 3.8 \\
$\mathrm{Cr}$ & 5.00 & 86.8 & 8.1 \\
$\mathrm{Cu}$ & 40.00 & 88.2 & 1.2 \\
$\mathrm{Fe}$ & 20.00 & 99.1 & 3.9 \\
$\mathrm{Li}$ & 40.00 & 83.5 & 26.3 \\
$\mathrm{Mn}$ & 20.00 & 86.4 & 4.3 \\
$\mathrm{~Pb}$ & 5.00 & 88.6 & 3.1 \\
$\mathrm{Sr}$ & 20.00 & 97.3 & 20.8 \\
$\mathrm{Zn}$ & 40.00 & 99.3 & 2.7 \\
& 40.00 & 92.3 & 56.2 \\
\hline auantification limit was established at lowest measured standard with accuracy error $>20 \%$
\end{tabular}


Table A. 5: Accuracy and precision for metal analyses on leachate and sediments

\begin{tabular}{lcccc}
\hline \hline & \multicolumn{2}{c}{ ICP OES $^{\mathrm{a}}$} & \multicolumn{2}{c}{ Metal extraction $^{\mathrm{b}}$} \\
Metal & Accuracy (\%) & Precision (\%) & Accuracy (\%) & Precision (\%) \\
\cline { 2 - 4 } $\mathrm{Al}$ & 91.2 & 2.3 & 67.9 & 5.1 \\
$\mathrm{Ca}$ & 104.4 & 4.6 & 96.8 & 7.9 \\
$\mathrm{Co}$ & 102.7 & 1.9 & 86.4 & 4.2 \\
$\mathrm{Cr}$ & 103.4 & 2.1 & 94.3 & 3.7 \\
$\mathrm{Cu}$ & 101.6 & 0.8 & 97.0 & 6.9 \\
$\mathrm{Fe}$ & 107.3 & 1.9 & 94.8 & 2.6 \\
$\mathrm{~K}$ & 73.6 & 5.3 & 84.2 & 21.5 \\
$\mathrm{Li}$ & 91.6 & 1.0 & 109.6 & 12.2 \\
$\mathrm{Mg}$ & 105.4 & 2.1 & 101.3 & 1.4 \\
$\mathrm{Mn}$ & 102.3 & 2.0 & 93.4 & 3.2 \\
$\mathrm{Na}$ & 80.1 & 9.4 & 89.8 & 19.4 \\
$\mathrm{~Pb}$ & 104.3 & 2.5 & 95.3 & 3.9 \\
$\mathrm{Sr}$ & 103.5 & 1.5 & 81.4 & 3.6 \\
$\mathrm{Zn}$ & 101.9 & 3.3 & 92.1 & 6.2 \\
& & & & \\
\hline \hline
\end{tabular}

${ }^{a}$ Used for metal quantification on the leachates. Accuracy and precision based on internal standards measured 8 times

${ }^{\mathrm{b}}$ Used for metal quantification on the sediments. Accuracy based on duplicate measurements of certified two materials (SUD1- Environment Canada; CRMLGC 6187). Precision based on duplicate measurements of certified materials (SUD1- Environment Canada; CRMLGC 6187) and two experimental samples that were also measured in duplicate.

${ }^{\mathrm{c}}$ Precision is defined here as percentage (100* standard deviation/ mean). 


\section{Box A. 1. Underestimation of metal mobilisation by air-filtering environmental colloids}

The present study assessed only $\mathrm{Fe}(\mathrm{II})$ on the unfiltered fraction of leachate. Most of other metal species, such as total $\mathrm{Fe}$, were assessed in terms of $8 \mu \mathrm{m}$ air-filtered metal as proxy to total metal leached. There was a correlation between filtered and unfiltered iron. However, a comparison of $\mathrm{Fe}(\mathrm{II})$ and total Fe leached reveals that the filtering reduces metal leached up to 100 -fold. In other words, this standard filtration procedure for evaluation of metal leaching from sediments may greatly underestimate the actual contamination potential. A possible explanation is that during the filtering process $\mathrm{Fe}(\mathrm{II})$ is quickly oxidized and starts to crystalize into colloidal forms that are retained by the filter. In fact, rapid precipitation of $\mathrm{Fe}(\mathrm{II})$ is well described for aerated water. Notwithstanding, such filtering is still common practice in leachate studies since it is required for ICP OES analyses.

Precipitation of Fe(II) might also affect other trace metals, which co-precipitate and adsorb to iron oxides-hydroxides. Therefore, data from this and other traditional studies on the filtered fraction must be seen with care. As some immobilisation processes might be still manifest on the filtered fraction, levels of metal leached may be greatly underestimated.

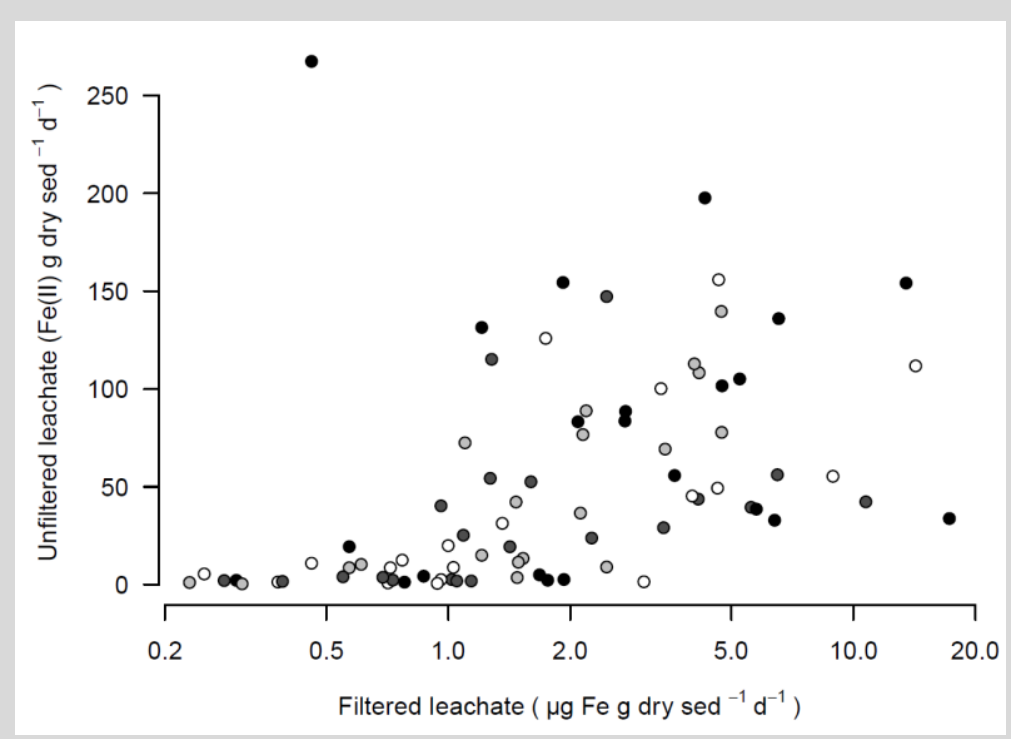

Figure: Comparison of unfiltered and $8 \mu \mathrm{m}$ air-filtered Fe. 
Supplementary Material B: Additional results

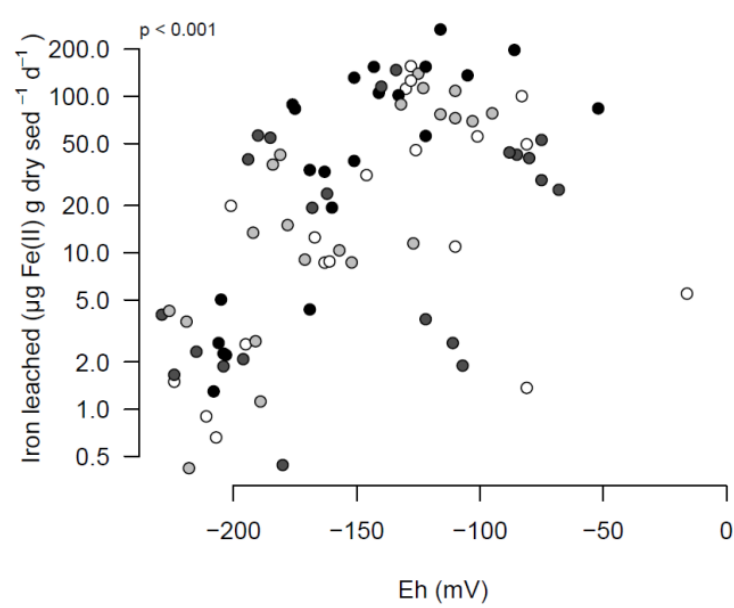

B

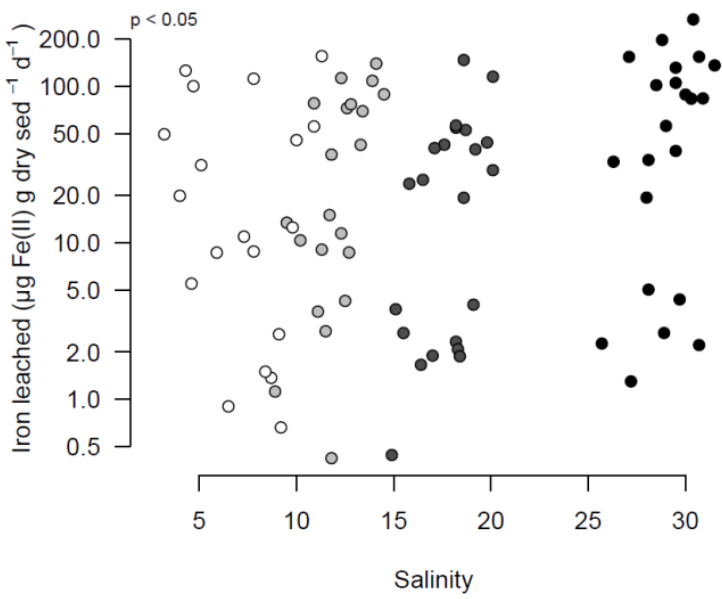

Figure B. 1: Effect of redox potential (A) and salinity (B) on the leaching of Fe(II). Maximum mobilisation occurs between -150 and $-50 \mathrm{mV}$. The white, light grey, dark grey and black filled circles represent respectively $0.000 \mathrm{~g}, 0.125 \mathrm{~g}, 0.375 \mathrm{~g}$ or $0.875 \mathrm{~g}$ of marine salt added to the experimental slurry. 

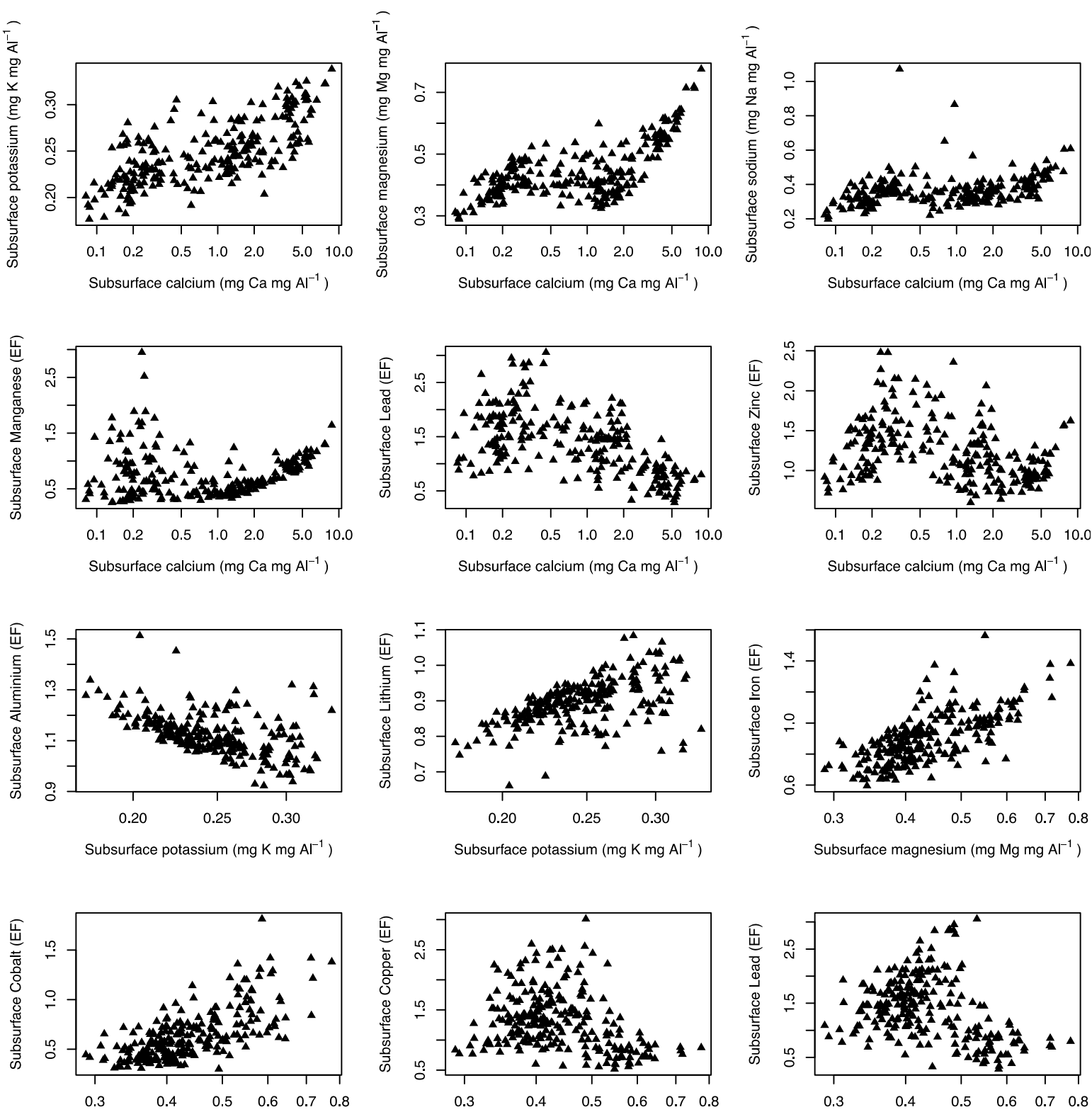

Subsurface magnesium ( $\mathrm{mg} \mathrm{Mg} \mathrm{mg} \mathrm{Al}^{-1}$ )

Subsurface magnesium ( $\mathrm{mg} \mathrm{Mg} \mathrm{mg} \mathrm{Al}^{-1}$ )

Subsurface magnesium (mg Mg mg Al ${ }^{-1}$ )

Figure B. 2: Selected relationships between geochemically normalised concentrations of alkali and alkaline Earth elements and levels of subsurface metal pollution (in terms of enrichment factor-EF). 
A

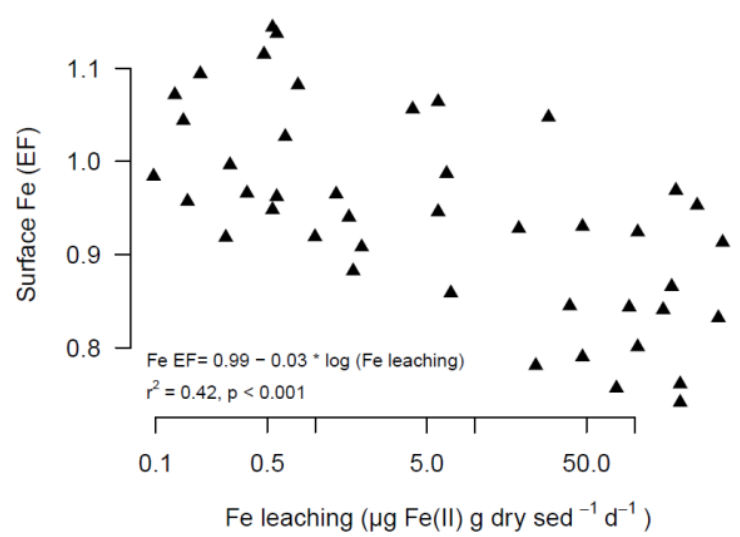

B

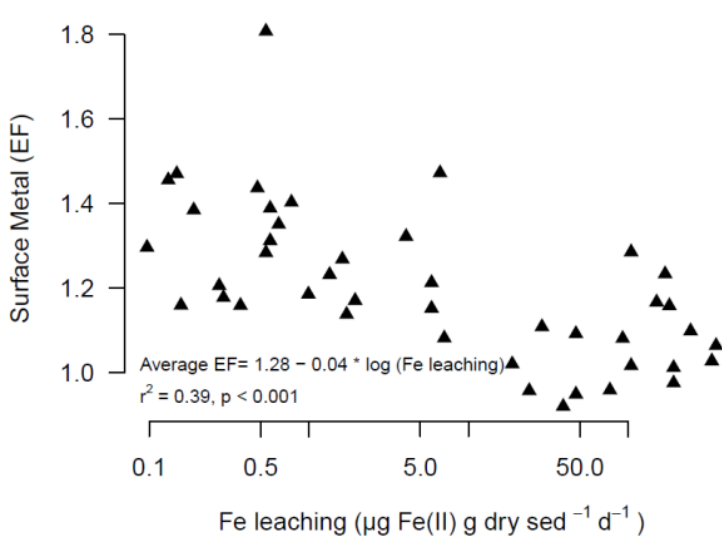

Figure B. 3: Effect of leaching of Fe(II) on the environmental pollution levels of surface sediments in terms of Fe (panel A) and average metal (average of Al, Co, Cr, Cu, Fe, Li, Mn, Pb, Sr, and Zn, panel B). 